\section{Claudio}

Barahona

Gallardo

\section{Universidad de}

los Andes, Chile

barahonameister@gmail.com

Recibido: 22.08.17

Aceptado: 21.10.17

\title{
Para una historia del precedente judicial en Chile: la recepción del artículo 3.0 del Código Civil en la doctrina del siglo XIX
}

\section{For a history of the judicial precedent in Chile: the reception of article 3 of the Civil Code in the 19th century doctrine}

Resumen: El propósito de este trabajo es exponer la forma en que el artículo 3. del Código Civil fue comprendido por sus primeros comentaristas, a la vez que nos referimos a su recepción por los autores de derecho procesal de la época. Comienza estableciendo los antecedentes relevantes sobre el tema en la época de transición entre el derecho indiano y el derecho civil codificado, continuando con el examen de las fuentes y de las obras de los juristas nacionales del siglo XIX. Esta revisión permite concluir que no era para ellos ajena la idea del precedente como fuente de derecho vinculante, si bien no todos eran partidarios de acogerla en la práctica habitual del foro ni tampoco estaban completamente de acuerdo con la posición que debía ocupar en la jerarquía de las fuentes del derecho. Palabras clave: Precedente, siglo XIX, doctrina, artículo $3 .^{\circ}$, Código Civil.
Abstract: The purpose of this paper is to explain the way in which article 3 of the Civil Code was understood by its first commentators, while we refer to its reception by the authors of procedural law of the time. It begins by establishing the relevant antecedents on the subject in the transition period between Spanish colonial law and codified civil law, continuing with the examination of the sources and works of the national jurists of the XIX century. This revision allows us to conclude that the idea of precedent as a source of binding right was not alien to them, although not all were in favor of accepting it in the usual practice of the forum nor were they completely in agreement with the position that should occupy in the hierarchy of the sources of law. Keywords: Precedent, XIX century, doctrine, article 3, Civil Code. 


\section{Palabras preliminares y status quaestionis}

Si tuviéramos que caracterizar el panorama actual del derecho procesal en nuestro país, configurado por las discusiones y problemas propuestos por quienes cultivan esta disciplina, no podríamos menos que admitir su complejidad y variedad. Muchas de sus investigaciones comienzan por la estructura y funciones de la judicatura, pero a poco andar esos límites son excedidos. Por lo demás, lejos ha quedado el tiempo en que la doctrina era la única que orientaba los debates. Ahora, aquellos que integran el Poder Judicial en calidad de jueces o que ejercen en él funciones técnicas opinan también desde sus respectivas experiencias profesionales.

Dentro de estos nuevos campos de estudio, debemos considerar especialmente los abiertos como consecuencia de la expansión de la judicatura en los últimos lustros: la ley № 19.911, del 8 de octubre de 2003, que creó el Tribunal de Defensa de la Libre Competencia; la ley $\mathrm{N}^{\circ} 19.968$, de 30 de agosto de 2004, por la que fueron creados los Tribunales de Familia; la instalación de los Tribunales Ambientales, por ley № 20.600 del 28 de junio de 2012; y, por supuesto, la Reforma Procesal Penal, de 2005. Estos hitos legislativos han motivado la producción de una extensa bibliografía, de todo punto destacable en términos tanto de volumen como por las ideas y conclusiones ofrecidas. No podría ser de otra manera, toda vez que los autores han comenzado a dar por superadas ciertas materias que, si bien revisten todavía interés pedagógico (como la distinción de los distintos procedimientos entre dispositivos e inquisitivos, por ejemplo), se han visto desplazadas por la implementación de los nuevos tribunales y sus respectivas leyes especiales, incluyendo la futura Reforma Procesal Civil y su correspondiente código ${ }^{1}$.

De esta manera, y con justa razón, los expertos se preguntan por el papel que tocará desempeñar a la Corte Suprema en este próximo escenario ${ }^{2}$, actuando por medio de los recursos contemplados en la reforma ${ }^{3}$, y lo que vendrá a significar el así llamado "gobierno judicial"4. Pero sin lugar a dudas, un lugar destacado en la discusión lo ocupa el precedente, que en cierto modo

\footnotetext{
1 En obras generales: De la Oliva, A. (2009) Casación, Oralidad y Nuevo Proceso Civil: Tres Conferencias Chilenas. Santiago: Ediciones Jurídicas de Santiago; Silva, J. P., García, J. F., Leturia, F. J. (Eds.). (2006). Justicia Civil y Comercial: Una Reforma Pendiente. Santiago: Libertad \& Desarrollo, Pontificia U. Católica de Chile. En artículos: Núñez, R. (2005). Crónica sobre la reforma del sistema procesal civil chileno (fundamentos, historia y principios). REJ, 6, 175-189; Rojas, M. (2009). Claves de la Reforma Procesal Civil. AJ, 20, 143-162; Romero, A. (2009). La Corte Suprema y la reforma procesal civil. AJ, 20, 61-77; Silva, J. P. (2013). Aspectos fundamentales del proyecto de Código Procesal Civil. AJ, 27, 101-131. Por supuesto, el proyecto no ha carecido de críticas: Alvear, J. y Covarrubias, I. (2013). Observaciones constitucionales al nuevo proyecto de nuevo Código Procesal Civil. AJ, 27, 27-59; Oberg, H. (2013). Proyecto de Código Procesal Civil: Prolegómeno. AJ, 27, 97-99; Rodríguez, P. (Enero de 2013). Reforma procesal civil: errores e inviabilidad. AJ, $27,9-25$.

2 Sobre el rol uniformador de la Corte Suprema en materia penal: Couso, J. (2007). El rol uniformador de la jurisprudencia de la sala penal de la Corte Suprema: anatomía de un fracaso. Revista de Derecho (Valdivia), XX (2), 147-172; Couso, J. y Mera, J. (2007). El rol uniformador de la jurisprudencia de la Sala Penal de la Corte Suprema: Estudio empírico. RIPr, 13 (1) 315-392; en materia laboral: Díaz, I. et al. (2014). Seguimiento del precedente por la Corte Suprema de Chile en materia laboral: Estudio empírico del recurso de unificación de jurisprudencia. RCHD, 41 (3) 1105-1131.

${ }^{3}$ En obras generales: Bravo, P. (2011). Unificación de jurisprudencia y recurso extraordinario en el proyecto de ley que establece un nuevo Código Procesal Civil (Memoria). Escuela de Derecho, Universidad de Chile, Santiago. Salinas, C. (2010). Nueva justicia constitucional: diálogo de competencias entre la Corte Suprema y el Tribunal Constitucional a la luz del recurso extraordinario del proyecto de ley para un nuevo código procesal civil (Memoria). Escuela de Derecho, Universidad de Chile, Santiago. En artículos: Becerra, P. A. (2012). Corte Suprema y recurso extraordinario: Algunas consideraciones de cara a la reforma procesal civil. REJ, 17, 197-231; Delgado J. (2012). El recurso extraordinario en el proyecto de Código Procesal Civil. RIPr, 18 (2), 125-146; Delgado J. (2012). La casación en la reforma procesal civil. RCsSVa. 60, 153-178; Delgado J. y Díaz, I. (2011). La unificación de jurisprudencia pretendida por el recurso extraordinario: Ventajas y problemas. RDUCN, 2, 275-304; Olguín N. (2012). El recurso extraordinario: ¿Una buena reforma? REDJD, $179-94$.

${ }_{4}^{4}$ Avilés, L. y Gallardo, E. (2014). Gobierno judicial: ¿Hay algo que gobernar? REJud, 1, 13-24; Bordalí, A. (2014). Propuestas para un nuevo gobierno judicial en Chile. REJ, 21 41-74; García, F. (2009). Corte Suprema y Gobierno Judicial: Un programa de reformas. AJ, 20, 81-122.
} 
enlaza y da cohesión a los restantes ${ }^{5}$. Se trata este de un tema que admite varias formas de aproximación. Así, tradicionalmente se le ha estudiado en su acepción de "jurisprudencia de los tribunales", como una fuente del derecho que, lo mismo que cualquier otra, debe ser sometida a jerarquización con el fin de precisar su alcance y fuerza (Squella, 2000, pp. 263-269) ${ }^{6}$, como también se le ha tratado respecto de la interpretación judicial (Ducci, 1995, pp. 87 ss.). Además, ha sido abordado desde su dimensión sapiencial (Pacheco, 1990, pp. 346 ss.), como un primer paso necesario para replantear, de cara a la reforma procesal, cómo entender el valor que tendrán las fuentes del derecho contenidas en Código Civil, lo que más de un autor ha puesto de relieve?

Como puede verse, a estas alturas cualquier estudio que verse sobre el contenido y la naturaleza de la función jurisdiccional y que se limite solamente al aspecto orgánico o procedimental de la misma estará de antemano condenado a la insuficiencia. $Y$ es que hoy en día se hace cada vez más necesario una visión de conjunto, que abarque de forma coherente e integral los temas previamente anotados. Queda de manifiesto al consultar la literatura relevante que el precedente judicial ha llamado poderosamente la atención de los autores, y que muchos de los trabajos que lo han tomado como objeto de estudio coinciden, en mayor o menor grado, en reconocerle un rol cada vez más importante como fuente del derecho. Esto significa, en definitiva, una referencia constante al artículo $3 .^{\circ}$ del Código Civil, nodo normativo que entrelaza toda la bibliografía ${ }^{8}$. Sin embargo, difícilmente puede encontrarse en ellos referencias históricas extensas sobre dicho precepto. Dado el sentido terminante en que se encuentra redactada la disposición y de su ubicación en el título preliminar, podría legítimamente preguntarse cuál es la historia de ella, o cuál fue su redacción original, o si acaso Bello siempre tuvo la convicción de confinar el alcance de las decisiones de los tribunales en la forma en que finalmente lo hizo. Ocurre con frecuencia que, aunque estas obras no ignoran completamente el contexto histórico en que se ideó y fijó la norma que nos ocupa, no se observa en ellas un tratamiento más detallado sobre el tema. Un trabajo que complementara las ideas generales a partir de la historia del derecho privado chileno no dejaría de revestir interés, sobre todo si con ello se procuraran elementos de análisis y discusión adicionales a los importantes debates que hemos apuntado más arriba. Precisamente, el objetivo de este artículo es ofrecer, si bien en forma esquemática, algunas apreciaciones sobre el artículo $3 .^{\circ}$ del Código y su recepción en la doctrina del siglo XIX.

Por supuesto, lo último nada tiene de nuevo. La noción de la jurisprudencia judicial como fuente del derecho, ya sea más o menos dinámica o vinculante, es tan antigua como el mismo código y se encuentra presente, por lo demás, en las fuentes de que Bello dispuso para tratar de

\footnotetext{
${ }^{5}$ Mención especial merece la bibliografía sobre el precedente, incluso cuando nos limitamos a la de origen nacional y de data más reciente. Obras generales: Romero, A. (2004). La jurisprudencia de los tribunales como fuente del derecho. Santiago: Editorial Jurídica de Chile; Romero, A. (2013). El Recurso de Casación en el Fondo Civil: Propuestas para la generación de precedentes judiciales. Santiago: Thomson Reuters. Véase en artículos: Accatino D. (2002). El precedente judicial en la cultura jurídica chilena. AFJS, 20, 559-582; Accatino D. (2011). La jurisprudencia de los tribunales en el derecho chileno: Fuente elusiva, fuente eludida. AFJS, 29, 79-98; Díaz, I. (2008). Condiciones de la sumisión al precedente. RDUCT, 9, 77-90, Díaz, I. (2015). Diez razones para incorporar el seguimiento del precedente en Chile. RDUCN, 2, 139-171; Marinoni, G. (2012). El precedente en la dimensión de la seguridad jurídica. RIPr, 1, 249-266.

${ }^{6}$ Vodanovic, A. (2001). Manual de derecho civil. Partes preliminar y general (2da. ed.). Santiago: Editorial Jurídica ConoSur Ltda., pp. 75 ss. 7 Por todos, Bravo-Hurtado, P. (2013). Hacia los precedentes en Chile: Reforma procesal Civil y fuentes del derecho. RCHD. 40 (2), 549-576. Explica este autor: "Este es un tópico recurrente en las ciencias jurídicas. La importancia, al menos fáctica - señala Alexyque tienen los precedentes también en el Derecho europeo-continental es hoy subrayada desde todos lados. Lo que se discute es su valoración teórica. La discusión se centra ante todo en la cuestión de si se les puede atribuir el carácter de fuente del Derecho, sin siquiera detenernos primero en si acaso estamos entendiendo lo mismo por 'precedentes' en una u otra cultura. Ahora bien, replanteárselo una vez más, ahora en Chile, es especialmente oportuno hoy en día. En marzo del 2012 se presentó al Congreso un proyecto de ley de nuevo código procesal civil. El proyecto, además de oralizar los procedimientos de primera instancia, propone eliminar la tradicional casación de ley. A cambio, se instauraría un tipo nuevo de recurso ante la Corte Suprema que está orientado a solo unificar la jurisprudencia en casos específicos. Esta reforma a la casación ha despertado una crítica severa: que a propósito de una reforma procesal se estaría alterando el sistema chileno de fuentes del Derecho. ¿Con estos nuevos recursos de unificación la jurisprudencia comenzará a ser fuente formal en Chile? Mas lo que corresponde a nuestra tradición jurídica es que la jurisprudencia no sea fuente del Derecho. Estas reformas procesales estarían, de paso, trastocando nuestra tradición" (pp. 549-550).
} 
la materia en el Título preliminar. Mucho más interesante para nuestro propósito es estudiar la recepción de la idea en las fuentes doctrinarias posteriores a su entrada en vigencia, ya sean las de los comentaristas del derecho civil y de los que podríamos llamar los primeros procesalistas nacionales, aquellos que fundamentalmente centraron su atención en la Ley de Organización y Atribuciones de los Tribunales de 1875.

\section{Algunas consideraciones sobre la jurisprudencia judicial en el período de transición}

Para entender con acierto la manera en que los autores de la época a la que nos circunscribimos interpretaron lo establecido en el artículo $3 .^{\circ}$, nos referiremos en primer lugar a los elementos que permiten apreciar la significación de esta norma una vez que el Código entró en vigencia. Para el período anterior a 1857, consideramos como tales los siguientes: i) La jurisprudencia en el derecho indiano; ii) la fundamentación de las sentencias; y iii) la historia del artículo 3.․

\subsection{La jurisprudencia en el derecho indiano}

Difícilmente podríamos hacernos una idea precisa de cómo actuaba el juez en el derecho indiano si lo sometemos a la forma actual de entender el rol del adjudicador. Por mucho que al día de hoy se permita al juez actuar con una flexibilidad que hace un siglo hubiera resultado impensada, de él sigue esperándose, invariablemente, el mayor grado posible de apego a la norma. Pero el de época indiana comprende el rol que debe cumplir de una manera totalmente distinta. No se le pedía la aplicación mecánica de la ley, lo cual le hubiera resultado, de todas formas, imposible: su cultura jurídica es la del ius commune, el derecho romano- canónico estudiado en las universidades europeas e hispanoamericanas, sustentado no en el estudio de la legislación vigente, sino en la opinión de los juristas. En este contexto, en donde el juez debe discurrir entre una pléyade de fuentes para encontrar la solución más adecuada, es lógico que la jurisprudencia no tenga un alcance absoluto, pues existiendo diversidad de autores, existe por supuesto diversidad de opiniones, situación de la que era perfectamente consciente el magistrado indiano (Bravo, 1991, Arbitrio judicial) ${ }^{9}$.

No debe creerse que recurriera en toda ocasión a las obras de doctrina, ni mucho menos que desdeñara el hacer cumplir las leyes o no tuviera en cuenta las costumbres jurídicas. El derecho común proporcionaba dos medios de juicio que tuvieron gran importancia en la práctica del derecho de Indias y en la manera en que el sentenciador debía aplicar las fuentes indicadas, cuales fueron la analogía y la equidad. Especialmente la segunda, pues era doctrina muy extendida en la época identificarla con la ratio, ya que ambas desempeñaban el rol de adaptación de la ley positiva a la realidad. Esto estaba consagrado ya en las Partidas, de vigencia muy

\footnotetext{
${ }^{8}$ En la jurisprudencia emanada de nuestras Cortes se ha elevado el así llamado "efecto relativo de las sentencias", contenido en este artículo, al nivel de un verdadero principio jurídico de alcance general. Así, podemos ver claramente la doctrina establecida1 al respecto por la Corte Suprema en "Hilda Valencia Montau contra INP": [Considerando 9.']: "La relatividad del efecto de las sentencias judiciales, que reconoce explícitamente el inciso segundo del artículo $3^{\circ}$ del Código Civil, es un principio jurídico general que, a la inversa de lo que se postula en el presente recurso, impide a la actora hacer valer el fallo que obtuvo la otra beneficiaria de la pensión que ambas perciben, para reclamar una nueva reliquidación del mismo beneficio, pues la sentencia dictada en el juicio que se llevó a cabo ante el Segundo Juzgado del Trabajo de Santiago sólo afectó a las partes del pleito y sus efectos no pueden extenderse a quien no tuvo esta condición". Este principio opera respecto del juez, quien no está obligado, en otro caso de similares características, a fallar de la misma manera en que lo hizo en un proceso anterior, pues en principio no son vinculantes para él sus propios fallos anteriores o los demás tribunales que se hubieran pronunciado sobre la materia. La sentencia comentada en Barrientos (2014, pp. 37-38).

${ }_{9}^{9}$ Ahora en Bravo, B. (2006). El juez entre el derecho y la ley (pp. 361-375). Esta libertad para sentenciar de que goza el juez indiano no debe ser sobredimensionada. Si bien el casuismo es una de las notas características del derecho indiano, lo mismo que la multiplicidad de fuentes disponibles para fundamentar sus dichos, el magistrado sujeta de todas formas su decisión al derecho vigente. Más preciso resultaría decir que la regulación viene dada no por el derecho legislado, sino que por el derecho común, sustentado en la opinión de los juristas, que le suministraban criterios y métodos, a través de las regula iuris. Tau V. (1992). Casuismo y sistema. Indagación histórica sobre el espiritu del Derecho Indiano (pp. 319-358, 486-541).
} 
extendida en América (Bravo, 1985, Vigencia de las Partidas, pp. 43-105), y que contenían una suerte de recurso extralegal, por el que se permitía a los jueces "desatar e toller del todos (...) si fallaren que las razones dé las leyes tiran más á mal que á bien"10. En otros casos, el juez se encontraba facultado por las mismas leyes para sentenciar dentro de un radio amplio, dando lugar así al arbitrio judicial, que en ningún caso debe ser confundido con arbitrariedad, pues al decidir debía ceñirse de todas maneras a ciertas reglas y preceptos propios del ius commune, que evitaban posibles excesos a la hora de aplicar e interpretar las distintas normas; destaca entre ellas la regla odia restringi, con un contenido y sentido muy determinados en época indiana, pero completamente transformada en el período de la codificación (Bravo, 1991, Arbitrio judicial, pp. 9-10)11.

Sin embargo, esta amplia libertad para la determinación del derecho aplicable no se condecía con lo expuesto en las sentencias. Una ley de 1778 recogida en la Novísima Recopilación ${ }^{12}$ había prohibido la fundamentación de estas, si bien la práctica de no motivar los fallos imperaba desde hacía tiempo en Castilla y en Indias (Levaggi, 1978, La fundamentación, pp. 45-74). Como explica Guzmán Brito, este fue el principal obstáculo para el desarrollo de una jurisprudencia judicial y, en consecuencia, la posibilidad de invocar los fallos a modo de precedente, pues no se explicitaban los motivos de las decisiones y por tanto muy poco era lo que, en ese sentido, podían citar juristas u otros jueces. En rigor, solían extenderse a las consideraciones de hecho y a los medios probatorios, omitiendo argumentaciones o razonamientos jurídicos. No puede, entonces, hablarse con propiedad de una jurisprudencia castellana o indiana aplicable como fuente del derecho en el Chile pre-republicano, si bien el papel de los tribunales fue de enorme importancia (Guzmán, 1982, Andrés Bello codificador, pp. 54-55), pues aunque nunca pudo constituirse en precedente vinculante, a través de las sentencias se adaptaba la letra de la ley a los casos concretos, fenómeno que en la América hispánica resultó natural atendiendo a la antigüedad que podían llegar a alcanzar las leyes en relación a las nuevas realidades a que ellas se veían enfrentadas ${ }^{13}$.

\subsection{La fundamentación de las sentencias}

La disposición de la Novísima a que nos hemos referido estableció el criterio legal en materia de fundamentación de sentencias que rigió en Chile hasta la dictación de la Constitución de 1822. En esta, en su artículo 219, ubicado en el título VII ("Del poder judicial"), capítulo IV ("De la administración de justicia i de las garantías individuales"), se dispuso: "Toda sentencia civil i criminal debe ser motivada". En la práctica, sin embargo, esta norma no llegó a tener efecto, pues solamente fijó el

\footnotetext{
${ }^{10}$ P. 1, 1, 18: "Como las leyes non deben ser desfechas sin causa razonable, e como se debe esto facer. Desatadas non deben ser las leyes, por ninguna manera, fueras ende si ellas non fuesen tales, que desalasen el bien que debían facer: é esto seria si oviese en ellas alguna cosa contra ley de Dios, ó contra derecho señorío, ó contra grand procomunal de la tierra, ó contra bondad conoscida. E por que el facer es muy grave cosa, y el desfacer muy ligera, por ende el desatar de las leyes, es tollerlas del todo que non valan, no se debe facer sino con gran consejo de todos los homes buenos de la tierra, los mas honrados, e mas sabidores, razonando primeramente los males que y fallaren, por que se deban toller; é otrosí los bienes que y son, é que pueden ser. E después que todo lo ovieren visto, si fallaren que las razones dé las leyes tiran más á mal que á bien, puedenlas desatar e toller del todo. E si fallaren que en el bien ha una gran partida, como quier que non iguale con el mal deben foller la soberanía del mal, é guardarlo con la bondad del bien, así que la bondad del bien e de la asperedumbre del mal nazca derecho bueno, e comunal: onde por todas las maneras que habernos dichas, e pueden desatar las leyes, é non por otras".

${ }^{11}$ Bernardino Bravo (2006, El juez entre el derecho y la ley. pp. 305-321).

12 Nov. Rec. 11, 16, 8: "Para evitar los perjuicios que resultan con la práctica, que observa la Audiencia de Mallorca, de motivar sus sentencias, dando lugar á cavilaciones de los litigantes, consumiendo mucho tiempo en la extensión de las sentencias, que vienen á ser un resumen del proceso, y las costas que á las partes se siguen; mando, cese en dicha práctica de motivar sus sentencias, ateniéndose á las palabras decisorias, como se observa en el mi Consejo, y en la mayor parte de los Tribunales del Reyno: y que á exemplo de lo que va prevenido á la Audiencia de Mallorca, los Tribunales ordinarios, inclusos los privilegiados, excusen motivar las sentencias, como hasta aquí, con los vistos y atentos, en que se referia el hecho de los autos, y los fundamentos alegados por las partes; derogando, como en esta parte derogo, el auto acordado 22, titulo 2. libro 3. á otra qualquiera resolución d estilo que haya en contrario".

${ }_{13}$ Ávila Martel estudió en profundidad el fenómeno del arbitrio judicial en el campo del derecho penal, observando que en el ámbito del derecho civil también se dio esta situación. Ávila, A. (1941). Esquema del derecho penal indiano. Santiago: Ediciones de la Universidad de Chile, p. 37 ss.; Dougnac, A. (1994). Manual de Historia del Derecho Indiano. Ciudad de México: Universidad Nacional Autónoma de México, pp. 262-263.
} 
criterio rector, pero sin implementar la correspondiente ley procesal que determinara el alcance de dicha exigencia y la forma en que los jueces debían darle cumplimiento. Con posterioridad, el presidente Prieto presentó al Congreso, en 1836, un proyecto de ley sobre fundamentación de sentencias, cuya tramitación quedó paralizada en la Cámara de Diputados debido al inicio de las hostilidades contra la Confederación Perú-Boliviana, pero que finalmente vio la luz al año siguiente por medio de un decreto con fuerza de ley, que vino en derogar el principio recogido en la Novísima al establecer que:

Toda sentencia se fundará breve y sencillamente. El fundamento se reducirá a establecer la cuestión de derecho o hechos sobre que recae la sentencia, y a hacer referencia a las leyes que le sean aplicables, sin comentarios ni otras explicaciones ${ }^{14}$.

El efecto de esta ley fue importante, pues con ella se impone a los jueces nacionales por primera vez la obligación de motivar sus fallos. Su dictación, empero, ofreció varias dudas a la Corte Suprema, ya que su brevísima extensión no daba respuesta para el problema de un eventual vacío legislativo. En consecuencia, este tribunal elevó por oficio de 11 de febrero de 1837 una consulta de doce puntos al Ministerio del Interior, a la sazón dirigido por Diego Portales, en la que se piden aclaraciones. Portales dio traslado de ella al fiscal de la Corte, Mariano Egaña, a fin de contar con su parecer. El informe que emitió a modo de respuesta, fechado en 20 de febrero de aquel mismo año, fue hecho suyo por el Ejecutivo, y sancionado como ley el $1 .^{\circ}$ de marzo, y en el cual se estableció "sirva de regla a todos los juzgados y tribunales del Estado a quienes toca la observancia de la ley a que son referentes las consultas de la Corte Suprema de Justicia"15.

Acerca de este dictamen, que terminó convirtiéndose en la segunda ley de fundamentación de sentencias, contamos hoy con una bibliografía que ha destacado sus más variados aspectos: su contenido, como una expresión de la legislación castellana vigente en la época, así como también una muestra de la alta cultura jurídica de su autor, bien versado en las obras de juristas hispanos, portugueses y franceses; e incluso el tratamiento que dispensó al derecho romano y la posibilidad de invocarlo como fuente en caso de vacío normativo ${ }^{16}$. En lo que a nosotros interesa, para Egaña resulta capital aclarar que la falta de ley expresa no es impedimento para que las sentencias se fundamenten, lo que al parecer constituía una práctica habitual que era necesario erradicar:

Que no puede dictarse sentencia alguna, sin que tenga fundamento, esto es, sin que existan razones y motivos bastantes que hayan obligado al juez a decidir tal cosa, mas bien que cualquiera otra. Estos fundamentos, se silenciaban hasta ahora; y la lei citada sin alterar el sistema de los juicios, ni los códigos en que deben encontrar los jueces la regla y motivo de sus decisiones, les manda esta razon que les obliga a decidir lo que aparece en su sentencia, ciñéndose (para evitar retardos y prolijidades inútiles o dañosas) a establecer la cuestión de hecho que motiva el pleito y sobre que recae la sentencia, y hacer referencia de la lei o leyes que le sean aplicables, sin comentarios ni otras explicaciones, propios mas bien de una disertación académica que de una sentencia (Anguita y Quesney, 1902, p. 295).

\footnotetext{
${ }^{14}$ Bravo Lira apunta sobre la semejanza estilística manifiesta entre esta disposición y el artículo 1213 del Código de Comercio español de 1829: "Los tribunales de comercio fundarán todas las sentencias definitivas e interlocutorias que pronuncien. Los fundamentos se reducirán a establecer la cuestión de derecho o de hecho sobre que recae la sentencia, y hacer referencia a las leyes que le sean aplicables, sin comentarios ni otras exposiciones" (Bravo, 2006, El juez entre el derecho y la ley en el mundo hispánico, p. 531).

${ }^{15}$ El texto de la ley, la consulta y el dictamen emitido a modo de respuesta aparecieron publicados en el Boletín de las leyes y de las órdenes y decretos del gobierno, 7 (1841), pp. 90-101. El texto del proyecto se publicó originalmente en El Araucano, en su número 325 de 25 de noviembre de 1836, recogido en Leyes promulgadas en Chile desde 1810 hasta 1901 inclusive (Anguita y Quesney, 1902, p. 275).

${ }^{16}$ Literatura sobre la ley: Bravo, B. (2006). El juez entre el derecho y la ley en el mundo hispánico (323-359). pp. 354-359; Figueroa, M. A. (1982). La codificación civil chilena y la estructuración de un sistema jurídico legalista. En Bello y el derecho (pp. 86-92). A. Andrés Bello codificador. pp. 88-95; Guzmán, A. (1982). Historia del "referimiento al legislador", II: el derecho nacional chileno. REHJ, 7 (107-130), 121-125; Hanisch, H. (1982). Contribución al estudio del principio y práctica de la fundamentación de las sentencias en Chile durante el siglo XIX. REHJ, 7 (131-172), 143-154.
} 
Como ha sido puesto de relieve por los autores, tanto la consulta elevada por el ministerio así como el dictamen del fiscal eran, en razón de su contenido, prelaciones de las fuentes del derecho vigente en la época (Anguita y Quesney, 1902, pp. 294-295) ${ }^{17}$. En ambos la ley ocupa un sitial de primacía y, en el segundo, recurrir a otras fuentes queda sujeto a la falta de norma expresa sobre el caso o a la imposibilidad de aplicar los principios de otras por vía analógica ${ }^{18}$; en lo que se refiere al empleo de las sentencias de otros tribunales, ello estaba expresamente planteado en el punto octavo: “¿Cómo se fundarán las sentencias cuando no hai lei ni analogía de otra, y solo se encuentran opiniones de autores jurisperitos o ejemplos de los tribunales de España?" (Anguitay Quesney, 1902, p. 295). Egaña no duda en invocar la legislación vigente para ofrecer una respuesta condicionada: a falta de ley escrita, aplicación analógica y costumbre, no pueden citarse directa y textualmente las opiniones de los autores ni las sentencias de los tribunales, sino que deben emplearse los principios generales del derecho que motivaron a los jueces a decidir en un determinado sentido. Para explicar esta suerte de despersonalización de los fallos, basta observar que la doctrina y la jurisprudencia son las fuentes en las cuales pueden propiciarse en mayor grado las discusiones eruditas, precisamente aquellas que Egaña quería alejar de las cortes y mantener para las aulas; guarda sentido, entonces, que la invocación de principios generales sea permitida y la cita textual prohibida. La regulación que hemos comentado subsistió hasta el 12 de septiembre de 1851, cuando se promulgó la Ley sobre acuerdos y fundamentación de sentencias, cuyo artículo $3 \mathrm{~N}^{\circ} 3$ disponía de la siguiente manera:

Toda sentencia definitiva o interlocutoria de primera instancia i las revocatorias de otro Tribunal o Juzgado contendrán: N. 3: Los hechos i las disposiciones legales, en defecto de éstas la costumbre que tenga fuerza de lei, i a falta de una i otra, las razones de equidad natural que sirvan de fundamento a la sentencia (Boletín de las leyes y de las órdenes y decretos del gobierno, 1851, 19, 524) ${ }^{19}$.

Resulta de gran importancia para nuestro trabajo, especialmente respecto de las leyes de fundamentación de las sentencias, referirnos a la publicación de la Gaceta de los Tribunales, la que puede ser considerada con toda razón como la primera revista jurídica de Chile ${ }^{20}$. Fundada en 1841 por José Gabriel Palma (1791-1869), y redactada por Antonio García Reyes (1817-1855) y Antonio Varas (1817-1886), sus páginas estaban destinadas a la publicación tanto de las sentencias de los tribunales de primera como de segunda instancia, así como de leyes, reglamentos, decretos y autos acordados, lo mismo que a la de artículos de doctrina y comentarios de sentencias. Desde 1860, sin embargo, la revista recogió exclusivamente las primeras. Su publicación fue la respuesta a la exigencia impuesta a los jueces en 1836 y confirmada nuevamente en 1837 y en 1851, de fundar sus sentencias, cifrándose en ello la esperanza de que estas habrían de quedar incorporadas al sistema de fuentes del derecho nacional. Pero en los hechos estas expectativas quedaron frustradas, pues la fundamentación se limitó a la cita escueta de las leyes aplicables, sin mayores razonamientos ni argumentaciones, y con escaso recurso a las otras fuentes permitidas por la tercera ley sobre la materia, que bien podían enmarcarse dentro de las "razones de equidad natural” (Guzmán, 1982, Andrés Bello, I, pp. 97-99). Como explicamos antes, esta práctica databa de época indiana, y se reforzó a consecuencia de lo

\footnotetext{
${ }^{17}$ En la consulta, el punto 2.0 trata sobre la costumbre; el 7.0 sobre el derecho romano; el 8.0 sobre la doctrina y la jurisprudencia de tribunales. En el dictamen, las fuentes del derecho aceptadas fueron las siguientes, en debido orden: la ley escrita vigente (de acuerdo a lo establecido en la ley I de Toro, considerando además las modificaciones introducidas por el derecho patrio); en su defecto, los principios generales y particulares de las leyes y la analogía; faltando ambos, la costumbre; y en ausencia de esta última, los principios aceptados por las sentencias de otros tribunales y la opinión de los juristas, incluyéndose el derecho romano entre aquellas. Véase Guzmán, A. (1982). Andrés Bello codificador, p. 90.

${ }^{18}$ Sin embargo, el legalismo de Egaña, aunque expresado en forma incuestionable a través de su informe, no llega a erosionar ni menos a demoler el sistema de fuentes vigente en la época de su dictación, lo que confirma que verdaderamente su objetivo era imponer la obligación legal a los jueces de fundamentar sus sentencias y no el prohibirles acudir a otras distintas de la ley escrita (Figueroa, 1982, La codificación, pp. 89-90; Guzmán, 1982, Andrés Bello codificador, pp. 91-92).

19 Vid. Merello, 1983, pp. 71-98.

${ }^{20}$ Sobre la Gaceta apreciada como publicación de interés científico, la bibliografía especializada es todavía escasa. Véase Brahm, E. (1991, pp. 45-56); Guzmán, R. (1983, pp. 159-269). También Carvajal (2012, pp. 180-183).
} 
preceptuado en las leyes de 1836 y 1837, que prohibían "comentarios y otras explicaciones", si bien tenemos noticias de que en algunos casos se aplicaron principios generales, con resultados cuestionables ${ }^{21}$.

La Gaceta de los Tribunales gozó desde sus inicios y durante toda su vigencia de una regularidad notable. Fue incorporada a la Ley Orgánica de Tribunales de 1875, en su artículo $95 \mathrm{~N}^{\circ} 3$, en que se ordena que el voto y fundamento de los ministros que no opinaran como la mayoría de la sala se publicarían en el referido periódico. Complementando lo anterior, por decreto de 20 de noviembre de 1878 se dispone que el objeto principal de la Gaceta es establecer la jurisprudencia práctica que se deduce de las sentencias pronunciadas en asuntos contenciosos. Su finalidad, en otras palabras, es dar a conocer la doctrina fijada por los tribunales (Hanisch, 1982, pp. 168-169). A partir de 1875, entonces, podemos comprobar la existencia de sentencias fundamentadas de manera más completa, si bien en la forma limitada que prescribió la ley.

\subsection{Historia del artículo 3.022}

Tan importante como conocer el sentido y los límites de la jurisprudencia judicial en el derecho indiano y los distintos cambios legislativos referidos a la fundamentación de las sentencias en el período republicano, es establecer la historia del artículo $3 .^{\circ}$ del Código Civil, sobre todo considerando que nuestra exposición versará especialmente acerca de dicha norma; su estudio, por consiguiente, requiere remontarnos hasta los antecedentes que Bello pudo haber tenido a la vista para decidirse por la redacción definitiva que conocemos hoy en día.

El Título preliminar del "Primer Proyecto" del Código (de fecha de redacción incierta, pero presentado por Bello a la Comisión de Leyes del Congreso en octubre de 1840) contenía un artículo 9 del siguiente tenor:
Los jueces pueden interpretar las leyes en cuanto aplicables al caso especial sometido a su conocimiento; y les es permitido fundar su interpretación en decisiones judiciales anteriores, pronunciadas por una Corte Superior o Suprema, y pasadas en autoridad de cosa juzgada; pero se les prohíbe dictar en sus fallos disposiciones generales (Ávila y Guzmán, A., 1978, pp. 141 ss.).

Como puede observarse, se trata en este artículo de una actividad interpretativa de carácter restringida, pues lo que justifica el ejercicio hermenéutico respecto de las leyes es su aplicabilidad al caso especial; seguramente, Bello está pensando en el litigio cuya solución no se encuentre en norma expresa, lo que guarda relación con lo dispuesto en la ley de fundamentación de sentencias de 1837, entonces en vigor. Por supuesto, lo destacable es que esta disposición permite la remisión específica a las sentencias de la Corte Suprema en la medida, como es lógico suponer, de que los casos sobre los cuales se pronunciaron compartan características similares respecto de los que el juez debe en su momento fallar, pues la letra del artículo no señala dicha circunstancia. En pocas palabras, esta autorización estaba particularmente condicionada, advirtiéndose además al juez que el resultado final de este ejercicio de aplicación e interpretación no podía tener el carácter de generalidad propio de una ley. Evitar revestir a las interpretaciones judiciales de un valor universalmente obligatorio, y confinar sus efectos solo respecto de la causa que las motivan, guarda perfecta coherencia con el principio medieval de la interpretatio necessaria sed non generalis, que Bello conocía a través de su expresión en los códigos modernos (Guzmán, A., 2011, p. 54). De todas maneras, puede observarse que, más que una verdadera regla de interpretación, lo que dispuso el artículo que comentamos fue una manera de fundamentar de las sentencias.

\footnotetext{
${ }^{20}$ Sobre la Gaceta apreciada como publicación de interés científico, la bibliografía especializada es todavía escasa. Véase Brahm, E. (1991, pp. 45-56); Guzmán, R. (1983, pp. 159-269). También Carvajal (2012, pp. 180-183).

${ }^{21}$ Así, Cosme Campillo (1826-1889) nos informa que con posterioridad a la entrada en vigencia de la ley de 1851, no era infrecuente que los tribunales fallaran invocando principios generales de forma vaga o sin conexión con el litigio, en el caso de ausencia de ley aplicable, lo que para muchos abogados y académicos era nada menos que un incumplimiento a la ley y una muestra de arbitrariedad (Campillo, 1863, pp. 110-116).

${ }^{22}$ Bibliografía para el estudio de esta materia: Ávila y Guzmán, A. (1978, pp. 141 ss.); Barrientos (2014, pp. 31-38); Guzmán, A. (2011, pp. 25-27).
} 
El "Primer Proyecto" no señala fuentes para este artículo 9 , y no se encuentra algún modelo en la legislación de la época. Claramente, cuando se le compara con el tenor del artículo $3 .^{\circ}$ de nuestro Código actual se advierte de inmediato una sustancial diferencia, explicable en parte porque cada uno tiene una finalidad distinta. El primero, como acabamos de señalar, ordena una manera de fundamentar las sentencias, mientras que el segundo, en opinión de Guzmán Brito, tuvo como propósito original prohibir los así llamados arrêts de réglement, de un modo similar a lo que había hecho el artículo 5 del Code (Guzmán, A., 2011, pp. 52-53)23, lo que se corresponde con lo que sabemos respecto de las fuentes del inciso $2 .^{\circ}$ del artículo 3. ${ }^{\circ}$ (Barrientos, 2014, pp. 31-32)24.

Nada de lo dispuesto en la redacción original del artículo 9 del "Título Preliminar" de 1840 llegaría al Proyecto de 1853 (Ávila y Guzmán, A., 1978, pp. 108$110)^{25}$. En este, las reglas de interpretación quedaron fijadas de casi idéntica forma a como terminaron por ser recogidas en el Código de 1855, descartándose establecer al mismo tiempo reglas que se refirieran a la fundamentación de sentencias. Bello y los restantes miembros de la Comisión Revisora estimaron que dicha materia, por su naturaleza, debía estar regulada en un código especial (Guzmán, A. 1980, p. 418) lo que en parte se cumplió en 1875. Especialmente sensible es la omisión, en el Código finalmente promulgado, de la autorización expresa concedida al juez para remitirse al precedente judicial (al menos al establecido por la Corte Suprema), sin que se hubiera establecido alguna norma equivalente. Podemos finalizar este apartado destacando que el estudio de la historia interna del actual artículo 3. ${ }^{\circ}$ desde sus fuentes conocidas más antiguas no permiten dudar que la intención original de Bello era, por lo menos en lo que respecta a la fundamentación de las sentencias, permitir el recurso de invocar el precedente (Guzmán, A. 2011, pp. 51-52), lo que guardaba consonancia con lo dispuesto en la ley sobre la materia de 1837 y en parte con la de 1851, que las admitía entendiendo de manera amplia la expresión "razones de equidad natural".

\footnotetext{
${ }^{23}$ Sobre los arrêts de réglement, explica Guzmán Brito: "La norma francesa fue pensada en función de abolir una práctica extendida entre los Parlamentos o altas cortes de justicia del Antiguo Régimen, consistente en emitir los denominados arrêts de réglement. Se trataba de decisiones solemnemente adoptadas, de donde que también se los llamara "arrêts en robe rouge", con valor erga omnes dentro del distrito jurisdiccional del Parlamento que las emitía. Su finalidad era suplir el silencio de las coutumes o de la legislación real, y no, pues, modificarlas o abrogarlas". Estos arrêts tenían valor provisional, y debían ser confirmados por el Rey por medio de la respectiva ley; solían ser emitidos con ocasión del fallo de una serie de casos litigiosos en que había resultado observada la laguna. "Estrictamente, tal práctica no era una vulneración al principio de la interpretatio necessaria sed non generalis, ni una manifestación tampoco del stare decisis (estar a las cosas decididas) o precedente judicial, sino una suerte de usurpación del poder legislativo del Rey, porque las mencionadas sentencias no tanto interpretaban sino que regulaban, ni valían en otros casos sino en cuanto contenían precisamente una regulación general. En contra de semejante usurpación reaccionó el artículo 5 CCFr., el cual quiso, en otras palabras, impedir que los tribunales emitieran normas generales". El artículo 5 del Code reza así: "Il est défendu aux juges de prononcer par voie de disposition générale et réglementaire sur les causes qui leur sont soumises": "Se prohíbe a los jueces pronunciarse por vía de disposición general y reglamentaria sobre las causas que le son sometidas".

24 "Descartadas las apuntadas en el Proyecto de 1853, se cuenta con la anotación que hizo el propio Bello en su "Comentario" a los primeros 76 artículos del Código, en la que señala "Código Francés, artículo 5", que contenía la prohibición de los jueces de pronunciarse, por vía de disposición general y reglamentaria, sobre las causas que le estaban sometidas. Además, lo mismo que en el inciso anterior, Bello pudo haber tenido a la vista la obra de Merlin".

${ }^{25}$ El artículo 9 permaneció inalterado, como artículo 11 en el Título preliminar del "Proyecto de 1841-1845", esto es, en aquél publicado en el periódico El Araucano entre el 7 de mayo de 1841(en el cual precisamente apareció el Título preliminar), y el 19 de diciembre de 1845, y que fue el resultado de las discusiones de la Comisión de Codificación de las Leyes Civiles creada en 1840, a que Bello fue sucesivamente presentando las diferentes partes del proyecto parcial de Código (justamente el "Primer Proyecto"), que había elaborado personalmente en la década anterior. En fin, como es sabido, el Título preliminar entero, y con él su artículo 11, desapareció en la segunda edición del "Proyecto de 1841-1845", que se denomina "Proyecto de 1846-1847", por haberse editado entre esos años.
} 


\section{La recepción del artículo $3 .^{\circ}$ en la doctrina del siglo XIX}

Como acabamos de ver, con anterioridad a la fijación definitiva de las fuentes del derecho aplicables por el juez en 1855, la jerarquía y prelación de estas estaba regulada por la ley de fundamentación de sentencias de 1837, que ofrecía un cuadro de pluralidad y, a partir de la cual, nada impedía que, en caso de ausencia de legislación aplicable, el juez pudiera recurrir a las sentencias dictadas por otros tribunales, lo que también era aceptable bajo el imperio de la ley de 1851. Sin embargo, cualquier tipo de tensión que existiera entre admitir o no el precedente judicial como una fuente del derecho vinculante para los jueces, terminó por inclinarse definitivamente por la negativa, a partir del título preliminar del Código, específicamente en su párrafo 1 (Guzmán, A. Andrés Bello, 1982, p. 457)26. Respecto del artículo $3 .^{\circ}$, finalmente restringió el valor de las sentencias judiciales a las causas en que actualmente se pronunciaren, con lo cual quedó eliminada la posibilidad de invocar la jurisprudencia judicial como fuente vinculante. Es cierto que Bello siempre tuvo una idea clara de sujeción de los jueces a la ley ${ }^{27}$, pero esto no significa que no hubiera considerado seriamente, al menos hasta 1845, la posibilidad de acudir a las sentencias de la Corte Suprema en caso de que no existiera ley aplicable sobre la materia litigiosa (entendiendo aquí "ley" en el amplio sentido del derecho indiano) (Dougnac, 1994, pp. 227). Esta situación sobre las fuentes del derecho terminó por fijarse con la versión definitiva del Código, por lo que, a partir de 1857, quedó establecido el criterio legalista de aplicación e interpretación por parte de los jueces (Lira, P., 1956, p. 60).
Lo que demanda nuestra atención en este apartado es estudiar, una vez que el Código entra en vigencia, la recepción del artículo $3 .^{\circ}$ por parte de la doctrina. En efecto, teniendo esta disposición el complejo trasfondo que acabamos de presentar, no resulta extraño que muchos fueran los autores que trataran sobre ella, desde la perspectiva del derecho civil o del procesal. En tales condiciones, resulta lógico esperar tanto coincidencia como disparidad en las opiniones, aunque todas comparten un común denominador, pues en ellas se aprecia una mayor o menor aceptación de la idea de permitir al juez invocar el precedente, estando condicionada esta posibilidad al grado de confianza que inspiraran los togados, considerando por lo demás la constante deficiencia en la fundamentación de las sentencias, circunstancia de la que ya dimos cuenta. Debe advertirse además que los autores de esta época no siempre emplean con rigurosidad las distintas categorías conceptuales pertinentes sobre la materia, lo que trae como consecuencia un tratamiento dispar de nuestro objeto de estudio: así, algunos lo consideran norma de interpretación, mientras que otros lo toman como manifestación del principio de separación de poderes, e incluso unos cuantos se refieren indirectamente a esta norma como un límite a la fundamentación de los fallos judiciales. De esto nos haremos cargo a continuación.

\subsection{El artículo 3. para los comentaristas del Código}

No está de más destacar que aquellos que redactaron las primeras obras de explicación e interpretación del Código pertenecen a una época de transición, entre

\footnotetext{
${ }^{26}$ La costumbre, por su parte, tenía en el Proyecto de 1853 un valor muy superior que al que, en definitiva, vino a reconocérsele en el Código finalmente promulgado.

${ }^{27}$ Acá es manifiesta la dualidad de Bello en este tema. Por una parte, habla en elogiosos términos respecto de los magistrados (1836, El Araucano 280) Ahora en Bello (1885, Administración de justicia. En Obras completas, pp. 89 ss.): "Reconociendo las cualidades que adornan a los signos individuos que componen la alta magistratura de Chile [...] nada es más a propósito para oscurecer el brillo de la magistratura y para envilecerla en cierto modo a los ojos de sus compatriotas y de las naciones extranjeras, que la dura necesidad en que está colocada de administrar un sistema vicioso, cuyos malos efectos se imputan sin razón a los jueces, en vez de atribuirse a las leyes y prácticas establecidas" (p. 92). Al mismo tiempo, no es concebible para ellos otra cosa que la completa sujeción a la ley: "Puede muchas veces al juez parecer una ley injusta; puede creerla temeraria; puede encontrar su opinión apoyada en doctrinas que le parezcan respetables, y puede ser que no se equivoque en su concepto; pero, con todo, no puede obrar contra esa ley, ni puede desentenderse de ella, porque si en los jueces hubiera tal facultad, no ya por las leyes se reglarían las decisiones, sino por las particulares opiniones de los magistrados." (Bello, 1836, El Araucano, 311, 201 ss.). Ahora en Observancia de la lei (1885, Obras completas, p. 292).
} 
una cultura jurídica basada en la opinión de los autores y una basada en la letra de la ley ${ }^{28}$. Por mucho que la obra de Bello no hubiera significado una ruptura total con el derecho romano-canónico ni con el indiano ${ }^{29}$, era inevitable que a partir de 1857 se introdujeran innovaciones para las cuales se requería de un tipo distinto de literatura jurídica, pensada especialmente para los estudiantes ${ }^{30}$. Este es el contexto en donde se desenvuelven los comentaristas (Guzmán, A. 1992, pp. 81-88), lo que no significa forzosamente, como tendremos ocasión de ver, que fueran los únicos que se pronunciaran sobre el tema.

Resulta a lo menos curioso que, a poco de promulgado el Código, una de las primeras voces en pronunciarse sobre el alcance y fuerza de la sentencia judicial haya sido la de un joven estudiante de reciente graduación, José Manuel Fernández Carvallo (1836-1890), quien publicara su memoria de licenciatura, Exposición del art. 1554 del Código civil, sobre la obligación que nace de la simple promesa de celebrar un contrato, i de una sentencia en que se relaciona con él, en las páginas de los Anales de la Universidad de Chile, de 1864. Más allá de lo que el título sugiere, el tema principal de su trabajo es introducido con la cuestión sobre el alcance de las decisiones judiciales, ofreciendo desde el inicio mismo su parecer:

Fijando el Código civil en el art. 3. ${ }^{\circ}$ la diferencia de atribuciones que al poder lejislativo i judicial corresponden acerca de la interpretación i explicación de las leyes, establece que, solo las que emanan del primero gozan de fuerza generalmente obligatoria, al paso que las del segundo la tienen, poco limitada no más que a cada una de las causas en que actualmente se pronunciaren. De este carácter limitado atribuido por la lei a las interpretaciones judiciales, se infiere claramente que las que sientan en sus decisiones los tribunales de justicia no vienen a ocupar en la jurisprudencia un puesto preferente al de una mera opinión privada. Será, si se quiere, mucho el respeto que ellas se merezcan, debiendo sobre todo considerárselas como el resultado de maduras deliberaciones; pero no basta esta circunstancia para que se defiera a ellas de un modo absoluto: supuesto que esta diferencia siempre había de ser mayor o menor, según que dichas interpretaciones anden más o menos acordes con el sentido i espíritu de las leyes sobre las cuales recaen. I no faltan a este respecto quienes crean que, en tratándose de la intelijencia de las leyes, es tanto más conveniente apartarse o prescindir del todo de interpretaciones judiciales (1864, pp. 810-811).

Lo que acabamos de transcribir merece por cierto algunos comentarios. Llama la atención en primer lugar que Fernández atribuya una naturaleza que podríamos llamar híbrida al artículo: por una parte, constitucional, cuando habla de los poderes legislativo y judicial, y por otra, civil, cuando habla de la aplicación de las leyes. Además, la idea un tanto difusa de que la interpretación judicial, en cuanto a su valor, se encuentra al mismo nivel que una opinión privada; probablemente está pensando en términos de jerarquía de las fuentes y quiso dar a entender que la sentencia del juez es similar en este sentido a la opinión del jurista. Finalmente, que cualquier

\footnotetext{
${ }^{28}$ Una destacable síntesis sobre las características de este periodo puede encontrarse en Baraona (2010, pp. 429-435) con notas.

${ }^{29}$ Tómese en cuenta el catálogo de fuentes de que se sirvió Bello para la redacción, entre las cuales predominaron indiscutiblemente las Siete Partidas, estudiadas por él con frecuencia. La vigencia de este cuerpo legal se mantuvo hasta bien entrado el siglo XIX. Al respecto, Bravo (1985). Para el resto de las fuentes, entre las que hay que considerar a la Novísima Recopilación, el Fuero Real y las Leyes de Toro, además de la antigua literatura jurídica del derecho castellano, Guzmán, A. (1982, Andrés Bello, pp. 414-421), con notas. También Martínez (2008, pp. 355-368). No queremos con esto (ni podríamos) desconocer el influjo que efectivamente tuvo el Code en los trabajos preparatorios a la redacción del Código Civil, en cuanto a su estructura y orden de materias, así como el ejercido por la literatura jurídica francesa, pues hay sobrada evidencia de que las obras de Pothier y Troplong, entre otros, fueron consultadas a menudo por Bello. Véase Ramón Domínguez Águila (2005, La influencia de la doctrina francesa en el derecho chileno. CAJ, 2, pp. 61-80). Para la recepción del Code en Hispanoamérica, Guzmán, A. (2005, pp. 27-60).

30 Innovaciones tales como, además de la idea de legalidad, la de libertad, principalmente mediante la acogida del concepto moderno de propiedad, lo que se manifiesta en varias disposiciones dentro del Código que eliminan las trabas propias del Antiguo Régimen a la circulación de los bienes, como los artículos 745, 769 y 982, y la libertad contractual y de la autonomía de la voluntad de las partes, consagrado en el artículo 1545; y también la idea de igualdad, esto es, que la ley solo reconoce a un sujeto de derecho, la persona humana, como se aprecia en los artículos 55, 57, 982 y 1446. Guzmán, A. (1982). Andrés Bello codificador, pp. 455-457. También Lira, P. (1956), pp. 7 ss.
} 
tipo de fuerza vinculante que la interpretación judicial aspire a alcanzar, la tendrá por su mayor adecuación con el espíritu y sentido de las leyes. Así vista, no podría menos que advertirse una suerte de hostilidad de parte de este memorista a la figura del juez, a tenor de la oscura referencia sobre los que sostenían una eliminación completa de la interpretación judicial. Pero Fernández se aleja de esta última postura, pues existen razones de utilidad que aconsejan su conservación, si bien en los modos impuestos por la ley:

No ignoro, sin embargo, que los tribunales, hallándose en el caso de ser consecuentes en sus resoluciones posteriores desde que han adoptado un parecer sobre una lei, no es fácil que se aparten de él: lo común será que lo sigan adelante como regla invariable para fundar idénticas decisiones. I es indispensable que razones poderosas están en favor de esta práctica, no siendo entre otras despreciable la de que, si a la oscuridad, inexactitud demás imperfecciones inherentes a las leyes humanas, se agregara de parte de los tribunales la falta de uniformidad en la aplicación de las mismas, en lugar de una fuente sola de litigios, habría dos, con la circunstancia de que la segunda vendría quizás a abrir un camino más expedito todavía para apoyar supuestas pretensiones (p. 811).

En otras palabras, la interpretación judicial debe ser preservada por dos razones: i) en la medida en que las Cortes fallen de acuerdo al tenor literal de la ley o de su espíritu, llegado el caso, se irá produciendo una tendencia que con posterioridad los tribunales de toda jerarquía inevitablemente adoptarán, aunque sea por motivos de comodidad; y ii) si llegara a restringirse en grado tal que en la práctica se eliminara, se generaría una situación potencialmente peligrosa, pues son los mismos tribunales los encargados de corregir las desviaciones que se producen cuando los jueces se apartan de la ley (dado que el Congreso y el Presidente no pueden revisar las sentencias pronunciadas). Ahora bien, debido a que la vasta mayoría de las memorias de licenciatura en el siglo XIX carecían de una bibliografía extensa, no estamos en condiciones de saber si las afirmaciones de que hemos dado cuenta fueron acuñadas originalmente por el mismo Fernández, pareciendo más probable que haya hecho suya una opinión común en la época. Por ello, lo que interesa aquí es observar cómo durante el resto del siglo se generó una corriente doctrinaria mayoritaria, que sostuvo firmemente la idea, más que de la primacía de la ley, la del verdadero alcance constitucional del artículo 3. .

Ya en las obras de los comentaristas, debemos comenzar, como no podría ser de otra manera, con José Clemente Fabres (1826-1908), quien publicó en 1863 sus Instituciones de derecho civil chileno, las cuales tuvieron una segunda edición corregida, en dos volúmenes, en 1893. En cuanto al contenido, esta obra se ciñe a la estructura de materias del Código, y de acuerdo a ella el autor ofrece comentarios sobre sus disposiciones. Pues bien, ¿qué nos dice sobre el artículo 3.? En la primera edición poco es lo que puede encontrarse sobre ello, pero su forma de enmarcar esta disposición fue modélica. En el contexto de la época, no existiendo una cátedra especialmente dedicada a lo que llamaríamos hoy "Teoría del Derecho", los autores solían destinar la explicación de los aspectos teóricos de la ley en la parte introductoria de los comentarios al Código o bien cuando comentaban las disposiciones del "Título preliminar". A propósito de esto, se refiere a la tripartición de las fuentes del derecho, en el que la sentencia judicial se encuentra desplazada por la ley y la costumbre secundum legem (en ese preciso orden). De ello no debemos sorprendernos. Fabres es el primero de una prolongada serie de autores para quienes la omnipotencia de la ley es una de las características más novedosas y relevantes del nuevo Código, y ello justifica el tratamiento preferente que se hace de dicha fuente del derecho por sobre las restantes ${ }^{31}$.

Más interesantes resultan los comentarios vertidos por el mismo Fabres junto a Enrique Cood (1826-1888), en sus respectivas lecciones, recogidas en las Explicaciones de Código Civil destinadas a los estudiantes del ramo en la Universidad de Chile, publicada en 1882. En ella hay una referencia más extensa sobre el artículo $3^{\circ}$, respecto del cual se destacan las dos perspectivas de análisis relevantes para los autores del período: i) la regla primordial de interpretación, en su inciso 1.; y ii)

\footnotetext{
${ }^{31}$ Fabres; J. C. (1863). Instituciones de derecho civil chileno. Valparaíso: Imp. del Universo de G. Helfmann, pp. 2-3.
} 
entender el artículo como una manifestación de la teoría de la separación de poderes del Estado. En efecto, así lo declaran expresamente. En cualquier caso, para estos autores el foco de atención está puesto en la interpretación realizada por los tribunales y el alcance que se debe dar a ella. Por supuesto, se encargan de exponer algunos ejemplos que representan excepciones para amplio sentido del segundo inciso del artículo 2..$^{\circ}$ (sobre la sentencia judicial que alcanza al deudor solidario, o la que se emite respecto del estado civil), pero:

fuera de los casos en que actualmente se pronunciaren las sentencias, la interpretación en ellas contenida i que se manifiesta en su parte resolutiva o es explicada en los considerandos que suelen precederla (en los que, en ocasiones, se hacen valer principios teóricos no consignados en la letra de la lei), no tiene más fuerza de la que tendrían sin esta circunstancia las razones aducidas (Cood y Fabres, 1882, p. 23).

Puede observarse que, de acuerdo con la experiencia de los autores, podían hallarse en su época sentencias en las cuales, ya fuera en su partes considerativa o resolutiva, se invocaran unos "principios teóricos" (no sabemos cuáles exactamente), que obedecían al propósito de fundamentar una interpretación de carácter extralegalista, la que, sin embargo, no tenía por ello más fuerza que la usual ${ }^{32}$. Parece ser que, al menos desde la perspectiva de Cood, si bien en ningún caso la interpretación judicial manifestada en una sentencia tendrá tal alcance como para llevarla a una abierta contradicción con la ley general, no debe desestimarse a priori su valor:

Ella debe considerarse como la opinión ilustrada e imparcial de personas inteligentes i prácticas que han sufrido un largo noviciado ántes de llegar a la magistratura, i que, por el objeto especial de sus funciones, han debido dedicarse a un estudio serio de la les leyes i de las reglas de interpretación (Cood y Fabres, 1882, p. 24) ${ }^{33}$.

Fabres reeditaría sus Instituciones en 1893, contemplando numerosas adiciones a su contenido, incluyendo también sus "Notas", que no eran otra cosa que comentarios extensos de determinados artículos. El $3^{\circ}$, a diferencia de la primera edición, le merece un examen detenido, pero su exposición viene a ser una verdadera lección elemental sobre teoría del Estado, más que una opinión desde el derecho civil. En ella, reafirma su idea acerca de dicha disposición como una expresión clara del principio constitucional de separación de poderes, del cual, por cierto, el legislativo "es el primero y el más alto de los tres Poderes; sus mandatos se denominan leyes y

\footnotetext{
${ }^{33}$ Vid. nota 21.

${ }^{32}$ Por lo demás, nos informa que en su época se tenía en el foro una elevada opinión de la interpretación judicial, debido fundamentalmente a la regularidad con que se publicaban las sentencias en el periódico oficial destinado para ello, la Gaceta de los Tribunales, que mucho contribuía a la difusión del contenido de las resoluciones judiciales entre aquellos que tuvieran interés en conocerlas. Aunque advierte, finalmente, que en caso de que al abogado o académico la interpretación judicial le pareciera errada, debe ser impugnada, "en la confianza de que la ilustración e integridad de nuestros Tribunales les harán volver a la verdadera doctrina, si llega a convencérseles de que se han apartado de ella". (la cita en p. 25). La idea de que las características personales y profesionales del juez constituyen un factor relevante a la hora de reconocer un peso adicional a sus sentencias se encuentra también en el derecho canónico (si bien tratada en términos distintos a los que los comentaristas del Código solían emplear, por razones obvias). Así, Lorenzo Robles (1817-1902), quien a propósito de su exposición acerca de los deberes específicos que deben cumplir ciertos miembros de la sociedad, se refiere especialmente al juez, a quien destina todo un capítulo (De las obligaciones de los jueces i reglas a que deben sujetarse en órden a las decisiones de las causas). Los jueces, como personas públicas que son, deben cumplir con su officium (deber) de acuerdo a ciertos principios de carácter teológico, del cual se destaca especialmente el II: "Todo juez para desempeñar cumplidamente los deberes de su oficio necesita estar adornado: 1, de una intelijencia no común para que pueda comprender bien la naturaleza de las causas; i dar a las leyes su recto sentido; 2, de ciencia suficiente para conocer las cuestiones de hecho i de derecho, debiendo estar versado tanto en las leyes patrias, como en las costumbres de los lugares i ordenanzas especiales, sin descuidar la lectura frecuente de la aplicación de las leyes en las sentencias de los demás jueces i tribunales superiores", confróntese su Concordancia de la teología moral con el Código Civil chileno, en los tratados de derecho, justicia i contratos (186, pp. 283-284). En Robles puede apreciarse con claridad el dualismo entre el juez-erudito y el juezaplicador, pues si bien es deseable que el letrado se encuentre instruido en el mayor grado posible, el objetivo de ello no es permitirle una interpretación creativa del derecho, sino que ejecutar la ley de la forma más estricta posible, y por eso es que debe estudiarla asiduamente: "por consiguiente debe saber que ha sido constituido, no para reformar ni mudar las leyes, sino para cumplirlas i hacerlas observar". Si se le permite alguna licencia en este respecto, es para los casos especiales en que el juez debe consultar más la intención de la ley que sus palabras (pero sin apartarse de ella), atendiendo ciertas características personales de las partes que acuden a él (p. 284). En términos similares, Justo Donoso (1857, pp. 206-207).
} 
obligan á todos los ciudadanos, inclusos los magistrados del orden administrativo y del judicial" (Fabres, 1863, Instituciones de derecho civil chileno, $2^{\mathrm{a}}$ ed. Notas $\mathrm{p}$. 177). Es por ello que las sentencias, en rigor, no crean derechos ni obligaciones como tales, sino que solamente declaran los primeros y hacen cumplir las segundas mientras estén establecidos por la ley; y no tienen más alcance que los dados por la causa para las que han sido emitidas. No existen, sobre la interpretación judicial o el precedente, mayores comentarios que los que podemos hallar en la primera edición.

Le sigue a Fabres y a sus Instituciones, Jacinto Chacón (1820-1898), quien publicó en tres volúmenes su Esposición razonada y estudio comparativo del código civil chileno. Lo mismo que su antecesor, y en concordancia con la opinión general de su tiempo, Chacón entiende que el título preliminar del Código debe ser comprendido a la luz de la teoría de la ley. Pero en vano se buscará en este autor alguna referencia especial sobre el precedente judicial. Pueden encontrarse, de todas formas, dos menciones acerca del juez y las reglas de interpretación, que permiten suponer un aprecio limitado de parte de este autor hacia los togados. La primera, sobre el artículo 23, que este autor entiende literalmente, y respecto del cual no duda en advertir que "Si bajo pretexto de equidad o de lo odioso i favorable, se permitiere al juez extender o restrinjir la lei fuera de los términos u objeto expresados en ella, pondríamos en sus manos un poder arbitrario, siempre peligroso" (1868-1882, pp. 39-40). La segunda, cuando se dan circunstancias tales en que no es posible aplicar las reglas de interpretación establecidas en el título preliminar, incluyendo la contenida en el artículo 24, y

la contradicción o la oscuridad subsiste i diere lugar a doctrinas diversas i a fallos contradictorios, la Corte Suprema de justicia i las Cortes de Alzada, en su caso, podrán dirijirse al Presidente de la República para que recabe del Congreso la declaración interpretativa correspondiente; i esto podrán hacerlo (...) pues esas Cortes no solo están facultadas sino que, por la naturaleza de sus funciones, están aún obligadas a dar cuenta al Presidente de la República de las dudas i dificultades que les hayan ocurrido en la intelijencia i aplicación de las leyes (p. 40).

¿Qué debemos entender de lo expuesto por Chacón? Si apreciamos sus ideas conjuntamente sobre el rol que cumple el juez, lo primero que establece son los límites respecto de su actividad, la cual no es otra que la interpretación (y únicamente esta), pero sin autonomía: incluso en los casos extremos en que no pueda aplicarse siquiera el artículo 24, se veda al juez de fundamentar sus sentencias en otras anteriores, y básicamente se estima como diligencia obligatoria acudir al Presidente como intermediario entre los tribunales y el Congreso, con el fin de solicitar una ley interpretativa; al decir "correspondiente", no excluye la posibilidad de que pueda pedirse concretamente para un caso singular, que por sus características peculiares tal vez no halló cabida en la legislación o incluso en la equidad.

Por su parte, también Robustiano Vera (1844-1916) en su Código civil de la república de Chile, comentado i esplicado, publicado en 1892, dedica algunas palabras sobre el artículo que estudiamos. Participa plenamente de la idea mayoritaria de su época, a saber, que esta disposición es en realidad la manifestación en un código de derecho privado de un principio constitucional ${ }^{34}$. Por ello,

Solo el Congreso tiene en Chile la facultad de dictar las leyes. A él también le corresponde interpretarla para que sea obligatoria, cuando en ella se noten vacíos. Los jueces deben solo aplicarla [la ley], tal como se promulga, sin poder salir de ella i sin darle otro alcance que aquel que ha sido la mente del legislador al dictarla, buscando para ello su orijen en los boletines de su formación (Vera, 1892, p. 3).

En pocas palabras, la interpretación judicial es para Vera un ejercicio en extremo restringido, pues i) solamente se justifica cuando existen vacíos normativos, y ii) debe manifestarse exclusivamente a través del referimiento al legislador, lo que de por sí es posible solamente por medio del estudio de los boletines (lo que llamaríamos

${ }^{34}$ Como lo sostuvieron también los cultivadores de derecho público contemporáneos de Vera (Lastarria, 1865, pp. 110 ss.; Roldán, 1913 , pp. 472 ss.) 
hoy en día la historia de la ley, documentada a través de las actas de las respectivas sesiones parlamentarias) (Vera, 1892-1897, Código civil, p. 4) ${ }^{35}$. Sin embargo, Vera se muestra inclinado a favorecer el rol de los tribunales como los genuinos intérpretes prácticos de la legislación, incluso en desmedro de la actividad hermenéutica llevada a cabo por juristas. De hecho, este autor no vacila en declarar que la facultad de que hablamos:

es derecho exclusivo y peculiar del Poder Judicial, así como el dictarlas e interpretarlas de un modo general para que sea obligatoria en toda la República, es obra del Congreso. Las sentencias judiciales forman la jurisprudencia práctica de los tribunales i de este modo se ve como se aplica i se entiende la lei. Esta jurisprudencia viene en último término a establecer la más autorizada intelijencia de la lei, pero sin que se entienda que de este modo se pueda arrebatar jamás sus funciones al Poder Lejislativo (Vera, 1898, p. 3).

Lo dicho por Vera apunta a la idea de que, si bien se debe tener una consideración especial con las sentencias emanadas de los tribunales, dicho miramiento no es extensivo a la doctrina, cuyas interpretaciones no constituirían, entonces, "la más autorizada intelijencia de la lei".

Tomás Ramírez Frías (1876-1946) también se hizo parte de esta forma utilitaria de considerar la labor de los jueces. Lo mismo que sus contemporáneos, para él carece de sentido tratar sobre la jurisprudencia fuera del marco de la teoría de la ley y de las fuentes del derecho. Sin embargo, Ramírez es realista al reconocer abiertamente la eventual insuficiencia de la ley para prever aquellos casos que, tarde o temprano, terminarán por sobrepasarla. Cuando esto ocurra el juez debe intervenir, estando obligado a ello por el artículo 9. ${ }^{\circ}$ de la Ley Orgánica de Tribunales a fallar las causas sometidas a su conocimiento; en caso de inexistencia u oscuridad de la legislación aplicable "debe buscar alguna solución en harmonía (sic) con el modo de ser de la sociedad. Estas resoluciones se van uniformando poco a poco, y la Corte de Casación establece las doctrinas de la Jurisprudencia" (Ramírez, 1907, p. 30). Tal vez sorprenda esta opinión, considerando la época en que fue pronunciada, sin embargo vimos en otros autores que no todos tenían una perspectiva tan estrecha sobre el rol del juez. Es cierto que para Ramírez las sentencias tienen efecto solamente para las partes del proceso, y nunca podrán tener alcance general, pero el juez no está indefectiblemente obligado a solicitar una ley interpretativa para cada caso (a diferencia de lo que planteaba Chacón), y podría, en la búsqueda de aquella solución socialmente armónica, tomar en consideración la doctrina establecida por la Corte Suprema. En pocas palabras, la jurisprudencia no puede en modo alguno llegar a tener el alcance general propio de la ley, pero su utilidad es manifiesta, y no puede prescindirse de ella.

El panorama que hemos descrito permite concluir, además, una especie de tensión doctrinaria en la época respecto del alcance del precedente judicial. Quien al concluir el siglo terminó por inclinar la balanza hacia la restricción no fue otro que Luis Claro Solar (1857-1945), a quien se le puede llamar el primero de los exégetas del Código. En lo que a nosotros ocupa, trató del tema en su capítulo sobre la teoría de la ley, en la que esta fuente ocupa un sitial indiscutido de primacía (Claro,

\footnotetext{
${ }^{35} \mathrm{Al}$ respecto, Vera lamenta abiertamente que los tribunales hubieran hecho caso omiso a lo dispuesto en el artículo 5.: "A este respecto debemos de esponer, que no se le ha dado exacto cumplimiento a este artículo. Se ha faltado abiertamente a él, y si los Tribunales hubieran cumplido con esta obligación año por año, existiría al presente un excelente acopio de material para mejorar nuestras leyes, lo que tal vez habría impelido la revisión que exijen". Sin embargo, compárese esta opinión con la que al respecto emiten Cood y Fabres: "Los efectos que ha producido la disposición de este artículo han estado léjos de corresponder a los propósitos del Lejislador. El presidente de la República no ha tomado en consideración las notas que han solido enviarles los Tribunales, lo que tal vez ha sido parte a que éstos descuiden el deber de que tratamos i se limiten a decir ordinariamente a decir que no les ha ocurrido ninguna duda, ni dificultad ni han encontrado ningun vacío en las leyes". Estos autores afirman que hacia 1868 las Cortes habían remitido informes al Ejecutivo con observaciones sobre los artículos 591, 854, 1420, 1618 número 1. ${ }^{\circ}, 1574,1801,2016$ y 2413 del Código, sin que al parecer hubieran recibido respuesta. Vid. Cood y Fabres (1882, p. 29).

36 "El Poder Judicial, que no tiene intervención alguna en la confección de la ley y ha sido creada para aplicarla, sea ella buena o mala". Claro Solar está lejos de ser el único en sostener este criterio rigurosamente legalista. En forma casi contemporánea, Juan Antonio de Armas (1854- ¿?) emplea un lenguaje similar cuando comenta, si bien brevemente, el artículo 3.: :Interpretación judicial es la que da el juez en las causas particulares que son sometidas a si conocimiento. Correspondiendo al Poder judicial por nuestra Constitución la aplicación de las leyes, sus sentencias no pueden ser obligatorias sino para las personas a quienes afectan las cuestiones de que el juez conoce
} 
1898-1944, p. 31) ${ }^{36}$. Para Claro Solar, la interpretación judicial solo tiene una autoridad de razón, que a nadie liga, por numerosos y repetidos que sean los fallos de los tribunales superiores que se pronuncien en el sentido indicado por los juristas. Pero en la práctica, por mucho que se sostenga la aplicabilidad de la ley en toda circunstancia, la jurisprudencia termina siendo el complemento de la legislación. Asegura que en gran medida ello se debe a los abogados, quienes "recurren fácilmente a las sentencias que resuelven el mismo punto de derecho, libertándose, de este modo del trabajo de discutir y establecer la doctrina legal" (Claro, 1898-1944, p. 130 $)^{37}$. Reconoce que la situación contraviene todo su planteamiento inicial sobre la separación de poderes: si el deber fundamental del juez consiste en aplicar la ley, ¿acaso no podría estimarse que, no existiendo aquella, el juez la crea al mismo tiempo que la aplica? En tal caso, admite prudentemente que:

es éste un inconveniente; pero mayor sería el de obligar al juez, como sucedía antes, a referirse al legislador para que dictase una ley que le sirviera para resolver el litigio. Esta referencia al poder legislativo tendría por resultado transformar al legislador en juez, lo que es más grave que transformar al juez en legislador, pues la independencia del legislador es más grande y su arbitrariedad mucho más peligrosa que la del juez (Claro, 1898, p. 33) ${ }^{38}$.

\subsection{El artículo $3 .^{\circ}$ entre los procesalistas}

Como habíamos anunciado más arriba, no fueron únicamente los comentaristas del Código los que se refirieron al precedente judicial. Pero es necesario realizar un esfuerzo por hallar puntos comunes entre ambas disciplinas al respecto, pues si bien entre los civilistas el artículo 3..$^{\circ}$ aparece tratado al mismo tiempo como manifestación de un principio constitucional y como regla de interpretación, esta disposición aparece muy pocas veces en las obras de quienes estudiaron el derecho procesal. Las razones que explican esta diferencia serán expuestas a continuación.

Al día de hoy sabemos que con anterioridad a que Bello iniciara su trabajo de codificación civil, fue el derecho procesal lo que primeramente demandó su atención (Bravo, 2006, pp. 449-451). A su llegada a Chile enfocó sus estudios en la administración de justicia, tema sobre el cual publicó entre 1830 y 1837 más de cincuenta artículos en las páginas del periódico El Araucano (muchos de ellos contenidos en sus Obras Completas). Desde el comienzo abogó por una reforma judicial, principal objeto de su preocupación en esos años: la Constitución de 1823 y el Reglamento de Administración de Justicia complementario de 1824 habían sido los instrumentos ideados para lograr implementar una serie de cambios que a la larga habían resultado contraproducentes ( $p$. 454).

actualmente; de otra manera, interpretando la lei de un modo generalmente obligatorio, usurparía las atribuciones de los otros Poderes" (1886, p. 18). Por su parte, Miguel Luis Amunátegui Reyes (1862-1949) declara que "no importa que se diga que [la ley] es injusta, inicua, o absurda [...] pues en todo caso tendrá que ser obedecida sic scripta est” (1891, p. 274). No debe considerarse al legalismo como algo completamente superado: casi cien años después, Enrique Correa Labra (1904-1993), en su calidad de presidente de la Corte Suprema, repitió casi a la letra las palabras de Claro Solar: "La ley la dicta el poder político -Poder Legislativo y Poder Ejecutivo- y ellos dicen lo que es justo, sin que sea permitido al juez discutir o dudar de la justicia que la ley encierra" (Bravo, El juez entre el derecho, p. 593).

${ }^{37}$ A propósito de esto, nuestro autor se pregunta acerca de la aplicación efectiva del artículo $5 .^{\circ}$ del Código, que en principio da pie para generar un proceso de obtención de una ley interpretativa. Como tal, la atribución contenida en dicha disposición es facultativa y de hecho, a juzgar por sus expresiones, los tribunales hacían caso omiso de ello y procedían a sentenciar basándose en sus propias interpretaciones, lo que per se no es equivocado (y de hecho es obligatorio, según el artículo 9..$^{\circ}$ de la Ley de Atribuciones de 1875) "En teoría - dice este autor - se puede decir que el legislador debe intervenir para fijar el sentido de las leyes, cuando en su aplicación existe tal contrariedad de decisiones que llegan a ser una fuente inagotable de procesos; pero la apreciación de la oportunidad de la intervención corresponde al mismo legislador" (p. 129). En la práctica, el artículo 5. no recibió aplicación en todo el siglo XIX, y Claro Solar da entender entre líneas que ello se debió a las mismas Cortes, que bien "no han querido llamar la atención sobre cuestiones que pudieran volverse a presentar a su fallo y en que estimaban peligroso dar opinión, sea porque han desconfiado de que el legislador pusiera inmediato remedio al mal por ellos señalado aumentando de este modo los conflictos y pleitos" (p. 34).

La fuerza de una sentencia es puramente moral, y pesará tanto como la ilustración o prestigio del magistrado que suscribe el fallo, lo que podríamos llamar la dimensión sapiencial de la interpretación judicial. La situación se mantuvo hasta bien entrado el siglo XX, en donde tenemos contados casos en que el artículo 5. recibió aplicación práctica (Andreucci, 2011, pp. 51-74).

${ }^{38}$ Estas ideas calaron profundamente en la doctrina de la época posterior. Así, Alessandri Rodríguez, cuarenta años después, toma al pie la tripartición de Claro Solar respecto del juez y el derecho aplicable, incluso invocando la figura del juez como "legislador momentáneo" (1936, pp. 27-29) y Pescio, en 1946, todavía trata de la diferencia entre ley y sentencia judicial, tal y como lo habían hecho los autores del siglo XIX (1948, pp. 207-208). 
El ilustre venezolano no se encontraba solo en sus afanes. Mariano Egaña (1793-1846), principal redactor del Reglamento de 1824 y fiscal de la Corte Suprema, fue el encargado de elaborar un Proyecto de ley de administración de justicia y organización de tribunales, que presentó en 1835 su primera parte, y que puede ser con razón considerado el primer trabajo codificador de Chile. Bello promovió frente al Consejo de Estado el examen de dicho proyecto, luego del cual se presentaron ante el Congreso como proyectos de ley separados varios de sus títulos, adaptados a la organización de tribunales ya existente. Pero estos proyectos nunca se despacharon, pues la tramitación se prolongó, y al estallar la guerra contra la Confederación Perú-Boliviana el Gobierno, en uso de facultades extraordinarias, promulgó proyectos pendientes: sobre implicancia y recusaciones, procedimiento ejecutivo, recurso de nulidad y, como ya lo vimos antes, sobre fundamentación de las sentencias ${ }^{39}$.

Una vez que Andrés Bello ha concluido su labor codificadora, y se comprueba la adecuada marcha de las leyes referidas a la administración de justicia, comienzan a aparecer los primeros procesalistas nacionales ${ }^{40}$. Entre ellos, destacamos en primer lugar a Francisco Vargas Fontecilla (1824-1883), quien en 1864 presentó su Proyecto de Lei de Organización i Atribuciones de los Tribunales, el que eventualmente se convertiría en la ley de 1875. La suya es una obra cuyo principal objetivo es llevar a buen término la serie de reformas parciales que Egaña había comenzado en 1824, por lo que es más bien poco lo que habla respecto del precedente (ni siquiera menciona el artículo $3 .^{\circ}$ del Código). Tenemos, sin embargo, una indicación acerca de este punto. Cuando habla de las innovaciones que experimentó la administración de justicia después de la Independencia, lamenta que entre ellas no estuviera la de erigir un tribunal de casación, pues:
Es ésta una necesidad universalmente sentida en Chile, i no dudo que tal innovación merecerá la aprobación unánime del público ilustrado. No puede concebirse un buen sistema de instituciones judiciales sin que en él figure un tribunal de alta jerarquía, que, revestido de una autoridad suprema, se halle encargado de corregir las interpretaciones viciosas de la lei, de fijar su verdadero i jenuino sentido, i de constituir i mantener de este modo la uniformidad de la jurisprudencia en todos los tribunales de la nación. Es nuestra actual Corte Suprema el tribunal de casación estatuido en el presente Proyecto (Vargas, 1864, p. xvii) ${ }^{41}$.

En su Prontuario de los juicios, José Bernardo Lira (1835-1886) se refiere indirectamente a la doctrina sentada por los tribunales, en términos mucho menos optimistas que los empleados por Vargas. En el Prólogo de la segunda edición, que aparece reproducido en las dos siguientes de 1880 y 1886, señala cuáles fueron los motivos que lo llevaron a escribir su obra, los cuales eran fundamentalmente pedagógicos (Lira, J. B. 1880-1881, pp. 5-6) ${ }^{42}$. A la vez que explica el método de composición y las fuentes consultadas, pronuncia una suerte de advertencia que sin duda debió llamar la atención en su época. Expresa que la naturaleza de su trabajo exigió la consulta de muchas sentencias (extraídas de la Gaceta de Tribunales, pues habla de la "ya abundante colección de las mismas"), pero que al momento de citarlas lo hizo de manera muy acotada, y que el criterio empleado para seleccionarlas fue que consignaran claramente una teoría o que aplicaran una regla sobre materias oscuras o incompletas en las leyes. La razón de ello fue:

alejar a la juventud de un escollo a que se siente fácilmente arrastrada; i del cual nos parece que, si no nos es dado alejarla absolutamente, debemos, por lo menos, enseñarla a desconfiar, porque es mui ocasionada a errores esta ciencia que se bebe en el

\footnotetext{
${ }^{39}$ En la época que referimos, Bello trató con insistencia sobre la publicidad de los juicios y, especialmente, de la fundamentación de las sentencias como la manera más idónea de dar a conocer los resultados de los litigios que, por sus características, revistieran de interés general (Bello, 1885, Publicidad, pp. 1-7; Necesidad de fundar pp. 279-285).

${ }^{40}$ El balance historiográfico en Bernardino Bravo (2006, El juez entre el derecho, pp. 415-447).

${ }^{41}$ En el tiempo en que Vargas presenta su proyecto, ya había abogado antes por la implementación del recurso de casación en el fondo, en su Discurso de incorporación en la Facultad de Leyes y Ciencias Políticas, recogido en el número de los Anales de la Universidad de Chile correspondiente a 1856.

42 Una de las razones esgrimidas fue la necesidad de proveer de un texto de estudio que viniera a complementar lo expuesto por Bernardino Vila en su propio Prontuario de los juicios, obra que tuvo dos ediciones, en 1844 y en 1857-1858 y que hacia 1867 estaba agotada.
} 
estudio de los fallos judiciales (pp. 6-7).

No son muchos los antecedentes que nos proporciona Lira como para saber hasta qué punto sus precauciones se encontraban justificadas, y aunque sabemos que la práctica de invocar el precedente judicial ante los tribunales generaba distorsiones doctrinarias, no sabemos exactamente cuáles podían ser tales ${ }^{43}$. Sí estamos en condiciones de apreciar que Lira no es hostil a la idea de que los abogados y estudiantes puedan remitirse a las doctrinas fijadas con cierta estabilidad, entendiendo los intervinientes que i) aquellas pueden variar con el tiempo; ii) que los jueces no deben abstenerse de hacer un examen del caso según sus circunstancias particulares, atendiendo a la realidad sin tener que forzarla dentro de una teoría preestablecida; y iii) ello se justifica solamente en caso de oscuridad o de leyes aplicables incompletas (pp. 7-8).

Una cita textual ofrecida por Lira nos permite detenernos en la obra de Francisco Ugarte Zenteno (1824-1907), autor con quien compartía su desconfianza respecto de la argumentación irreflexiva ante tribunales. Ugarte es especialmente crítico no tanto de la idea de que la doctrina establecida en sede judicial tuviera un efectivo valor, sino más bien de la práctica (aparentemente habitual en su época, a juzgar por sus expresiones) de invocar la jurisprudencia de casos anteriores sin tomar en consideración las transformaciones que en ella podían suscitar nuevos hechos o circunstancias, o incluso citarla en contra de disposiciones legales vigentes:

Los tribunales superiores cuyas sentencias se buscan con ahinco i se invocan por algunos con mayor confianza que las leyes mismas, deben mirarse mucho para sentar teorías o aplicar las existentes, por lo mui trascendental que es un error cualquiera de su parte. Cuando se conoce la interpretación que un tribunal da a la lei, los contratantes procuraran consultarla en sus documentos, i quedan ademas innumerables derechos sin ventilarse, porque generalmente se cree estéril toda discusion que traiga en su contra el antecedente de una doctrina opuesta de parte de los Tribunales (Ugarte, 1869, pp. 11-12).
Ugarte, de hecho, incentiva la crítica y el examen de las sentencias por parte de los abogados, pues ello es el medio más adecuado para lograr que las doctrinas sustentadas por los tribunales puedan variar con el tiempo, por mucho que parezcan arraigadas, particularmente cuando puede apreciarse en ellas errores que bordeen lo antijurídico. Podríamos decir incluso que este autor predica con el ejemplo: precisamente los capítulos II y III de la parte primera ("Advertencias e ideas generales") de su obra están destinados a llamar la atención sobre un caso de 1868 en el que se declaró la naturaleza jurídica mercantil de cierto contrato, en abierta oposición, según Ugarte, a los postulados fundamentales del derecho comercial y con lo dispuesto en el Código del ramo, de 1865. Ante esto, no puede menos que llamar la atención sobre la situación e intentar:

escribir algo para impedir, siquiera con la débil protesta de mi palabra, que nuestro código de comercio, en los primeros días de su existencia, empezara a ser interpretado i aplicado en un sentido que tanto se aparta de sus disposiciones (Ugarte, 1869, p. 13).

Tanta suspicacia le genera la doctrina establecida por los tribunales que llega tan lejos como para afirmar que el ejercicio continuo de atenta vigilancia que deben ejercer los abogados y juristas sobre las sentencias "sería quizá más fructuoso entre nosotros que lo que pudiera serlo una corte de casación" (p. 13).

Por supuesto, entre quienes cultivaron el derecho procesal no se puede dejar de mencionar a Manuel Egidio Ballesteros (1844-1914), y su obra La lei de organización i atribuciones de los tribunales de Chile, de enorme influencia en la época de su publicación y hasta bien entrado el siglo siguiente. A través de su comentario del artículo $4 .^{\circ}$ de dicha ley, se confirma la idea de que, más que una regla de interpretación, al artículo $3 .^{\circ}$ del Código se le consideraba una disposición de contenido constitucional. Es cierto que el interés principal de Ballesteros se encuentra en los aspectos orgánicos de la ley, principalmente las cuestiones de competencia y las diferencias entre la judicial y la administrativa (1890, pp. 27-42), pero lo mismo que con su antecesor Vargas

${ }^{43}$ Vid. supra, nota 21. 
Fontecilla, vale la pena leer con cuidado su breve, pero reveladora observación sobre la jurisprudencia:

Aunque la jurisprudencia no desempeña todavía en Chile el importante papel que se le ha asignado en los países más adelantados, i especialmente en Inglaterra, nosotros, siguiendo el sistema que nos hemos propuesto en esta obra, vamos a resumir brevemente las principales resoluciones dictadas por el Consejo de Estado en cuestiones de competencia entre autoridades administrativas i judiciales desde la promulgación de la Lei Orgánica de Tribunales. La jurisprudencia del Consejo de Estado, cuyas resoluciones han sido redactadas de ordinario con un lamentable laconismo, no es menos digna de ser conocida que la de los tribunales de justicia, aun cuando la extrema brevedad de las sentencias i la insuficiencia de los motivos en que se fundan no arrojen a veces la luz necesaria para comprender los principios jenerales a que obedecen (Ballesteros, 1890, p. 27).

El párrafo transcrito se explica por su contexto: Ballesteros tiene como propósito principal poner de relieve el estado de la cuestión, hacia 1890, sobre la diferenciación de funciones establecida en el artículo 4. ${ }^{\circ}$ de la Ley Orgánica (p. 20) ${ }^{44}$, que no es otra que los conflictos de competencia entre las autoridades administrativas y las judiciales ${ }^{45}$. Pero reviste de interés para nuestro estudio observar que i) en las primeras líneas no está hablando sino del precedente judicial, a juzgar por la alusión específica que hace del sistema judicial inglés; y ii) sus palabras reflejan el principal obstáculo que siempre tuvieron las sentencias para alcanzar un papel más relevante como fuente del derecho: su escasa fundamentación ("extrema brevedad" e "insuficiencia de los motivos"). Es destacable, asimismo, que Ballesteros no parece descartar a priori la posibilidad de que, corrigiéndose el problema que él identifica, las sentencias pudieran llegar a servir como precedente, a condición de ser fundamentadas en forma más completa; al parecer se está refiriendo en especial a aquellas que se pronuncian sobre casos no contemplados en la ley, o cuando no existe norma aplicable, según podemos inferir de su alusión a los "principios jenerales".

Finalmente, contamos con la obra de Carlos Risopatrón (1850-1926), tal vez el ejemplo más claro que, incluso al comenzar el siglo XX, persistía en el medio jurídico nacional la idea de que la jurisprudencia de los tribunales ejercía una suerte de atracción natural, confirmada por la práctica habitual en el foro ${ }^{46}$. En las primeras páginas de su Comentario a la Ley de Organización de los Tribunales ofrece una breve teoría de la función jurisdiccional, con el fin de indicar los precisos límites de este poder, y las razones que lo llevaron a excluir las sentencias judiciales como objeto de estudio de su obra:

En cuanto a la jurisprudencia resultante de las sentencias de los Tribunales, no ha entrado ni podido entrar a completar nuestro plan [exponer el contenido de la ley de forma esquemática para los estudiantes de los Cursos de Leyes]. Por una parte, ella es de suyo variable, no siempre uniforme, y para descartar lo que la hace aprovechable, que es la interpretación doctrinal de la ley en ella contenida, necesita criterios más ejercitados en desentrañar los principios de derecho y las razones legales o de equidad, que son los que dan a las sentencias su valor jurídico e ilustrativo de la ley. Y por otra parte, ella es tan múltiple y voluminosa, que es preciso reservarla para obras de mucha mayor extensión (Risopatrón, 1900, pp. 6-7).

Como señalamos, el propósito de Risopatrón a través de estas líneas era esclarecer al lector el motivo de la ausencia de jurisprudencia en sus Comentarios, pero

\footnotetext{
${ }^{44}$ El artículo $4 .^{\circ}$ de la Ley de Orgánica de Tribunales y el 3..$^{\circ}$ del Código no eran en lo absoluto las únicas disposiciones que establecían diferenciación de funciones. Ballesteros concuerda el artículo $4 .^{\circ}$ de la Ley con "[las disposiciones] consignadas en la lei de Réjimen Interior de 22 de diciembre de 1885, que prohíben a los gobernadores ejercer funciones judiciales o resolver asuntos contenciosos, i les permiten promover competencias en resguardo de sus atribuciones [...]. Por su parte, la Corte Suprema dictó, el 22 de diciembre de 1863, un auto acordado con el objeto de reglamentar la forma en que los majistrados judiciales deben entablar las competencias". Igual concordancia hallamos en Coo Tagle, Alberto, Concordancias de la Lei de Organización i Atribuciones de los Tribunales con la lejislación chilena (Santiago, Imprenta i encuadernación Roma, 1896), p. 8.

${ }^{45}$ A los que alude Robustiano Vera, sin duda en relación al comentario de Ballesteros (Vera, 1894, Ley de Organización, p. 9).

${ }^{46}$ Vid. nota 36.
} 
lo hace al mismo tiempo que le advierte cuáles son los problemas que el abogado enfrentaría al elevarse aquella en la jerarquía de las fuentes, entre otros: i) falta de uniformidad en las decisiones finales; $y$ ii) falta de claridad en los criterios empleados como fundamentos. Por supuesto, no puede pasar por alto el problema generado cuando un tribunal es llamado a actuar inexcusablemente y no hay ley expresa que resuelva el conflicto, pero "en tal caso nunca faltarán principios jurídicos en que fundar las sentencias". Continúa con una brevísima exposición acerca de los elementos que pueden ser considerados como válidos para la fundamentación de un fallo de esta naturaleza:

Nunca las sentencias de los tribunales ni las opiniones de autores. Pero sí las razones o fundamentos de derechos que unos ú otros hayan tenido para fallar $u$ opinar como lo han hecho, junto con el fundamento que hace fuerza ó decide al juez a abrazarlos en el sentido de su resolución (pp. 28-29).

Puede resultar confuso comprobar que, a la vez que niega a la doctrina y a la jurisprudencia valor suficiente para reemplazar por sí mismas a la ley cuando debe fundarse una sentencia en ausencia de esta, declara que es perfectamente posible emplear las razones 0 fundamentos jurídicos a los que se remiten los autores o jueces. A modo de explicación, advirtamos que este autor no está haciendo otra cosa que una referencia al orden de prelación de fuentes del derecho de la ley de fundamentación de la sentencias de 1837, en su época hacía mucho derogada, lo que nos hace pensar que la consideraba, en razón de su contenido, más completa que la de 1875.

\section{Conclusiones}

Como se ha podido apreciar, muchos son los factores que deben considerarse para hablar desde una perspectiva histórica del precedente judicial en Chile, y no se puede concluir de otra manera que no sea admitiendo que el examen de las leyes sobre fundamentación de sentencias dictadas en el siglo XIX resulta esencial. Además, la redacción original que Bello estableció para el que eventualmente se convertiría en el artículo $3 .^{\circ}$ del Código hoy vigente, permitía acudir al precedente judicial en busca de fundamentos para sentenciar. El artículo podía ser entendido, dentro de todo, por el ambiente jurídico imperante en aquella época, que toleraba la pluralidad de fuentes aplicables al caso particular. Pero Bello, según comprobamos, terminó por cambiar de parecer hacia 1845, pues en el Proyecto de 1853 nada hay sobre fundamentación. Sostengo que el principal factor que explica esto fue que, hacia el período final de redacción, la materia ya estaba regulada en una ley especial de fundamentación, y que prefirió darse un tratamiento preferente a las reglas de interpretación en el Código.

Por otra parte, vimos que la inobservancia de las sucesivas leyes de fundamentación de la sentencias generó sucesivas críticas de parte de los autores, ya fuera porque su incumplimiento daba pie al establecimiento de doctrinas poco fiables, o porque los jueces toleraban prácticas recurrentes en las Cortes respecto de la invocación irreflexiva de sentencias anteriores, lo que en ambos casos frustraba las expectativas de quienes, como Bello, no miraban con malos ojos que la jurisprudencia alcanzara un grado de estabilidad suficiente como para servir de verdadera fuente del derecho: cuando el primer número de la Gaceta de los Tribunales estaba ad portas de ser publicada, fueron muchos los abogados, jueces y académicos que se formaron altas ideas de lo que podía lograr a lo largo del tiempo, como principal medio de difusión y publicidad de las sentencias.

Pero a pesar del tenor terminante que nuestro objeto de estudio acabó por adquirir en el Código definitivo, no podía preverse que terminaría teniendo un valor cuasiconstitucional, una verdadera manifestación del principio de separación de poderes, siendo que en sus orígenes Bello intentaba a través de él simplificar el elenco de fuentes aplicables por los jueces, y de ningún modo reforzar la Carta Fundamental de 1833. Cierto es que fue un fiel reflejo de las ideas rectoras que Bello tenía 
para la administración de justicia y para la primacía de la ley. Pero si bien estas eran las ideas matrices, nos consta por medio del examen de las obras publicadas con posterioridad a la entrada en vigencia del Código, que fueron, dentro de todo, discutidas por la doctrina, que entendió esta disposición como una regla cardinal de interpretación de la norma en la actividad aplacadora del juez. Finalmente, destacamos que este trabajo bien puede servir para formar una idea más clara de lo que significa la recepción de innovaciones legislativas en el ámbito de la administración de justicia, a través del examen de las fuentes de la época, con el fin de realizar una estimación que, a no dudar, resultará ilustradora para nuestro propio tiempo y circunstancias.

\section{Referencias}

Alessandri, A. (1936). Derecho civil. Primer año. Santiago: Editorial Zamorano y Caperán. I.

Amunátegui, M. L. (1891). Definición de ley. Revista Forense Chilena, 5.

Andreucci, R. (2011). La aplicación del artículo 5 del Código Civil en los discursos de los presidentes de la Corte Suprema desde 1951 a 2010, en Salinas C. (Editor académico) Libro de amigos dedicado al profesor emérito ítalo Merello. Valparaíso: Ediciones Universitarias de Valparaíso.

Anguita, R. y Quesney, V. (1902). Leyes promulgadas en Chile desde 1810 hasta 1901 inclusive. Santiago: Imprenta Nacional.

Ávila, A. (1941). Esquema del derecho penal indiano. Santiago: Ediciones de la Universidad de Chile.

Ávila, A. y Guzmán, A. (1978). El "Primer Proyecto de Código Civil de Chile". Santiago: Editorial Jurídica de Chile.

Ballesteros, M. (1890). La lei de organización i atribuciones de los tribunales de Chile. Santiago: Imprenta Nacional, I.

Baraona, J. (2010). La cultura jurídica chilena: apuntes históricos, tendencias y desafíos. RDPUCV, 35.

Barrientos, J. (2014). Código Civil. Edición concordada con observaciones históricas, críticas. Santiago: LegalPublishing-Thomson Reuters, I.

Bello, A. (1885). Administración de justicia. En Obras completas. Santiago: Impreso por Pedro G. Ramírez, IX.

Bello, A. (1885). Necesidad de fundar las sentencias. En Obras completas. Santiago: Impreso por Pedro G. Ramírez, IX.

Bello, A. (1885). Observancia de la lei. En Obras completas. Santiago: Impreso por Pedro G. Ramírez, IX.

Bello, A. (1885). Publicidad de los juicios. En Obras completas, Santiago: Impreso por Pedro G. Ramírez, IX.

Boletín de las leyes y de las órdenes y decretos del gobierno. (1851). 19.

Boletín de las leyes y de las órdenes y decretos del gobierno. (1841). 7.

Brahm E. (1991). Los comienzos de la primera revista jurídica chilena: la Gaceta de los Tribunales entre 1841 y 1860. REHJ, 14.

Bravo, B. (1976). Los estudios sobre la judicatura chilena en los siglos XIX y XX ahora en Bravo, B. (2006). El juez entre el derecho y la ley. Santiago: LexisNexis.

Bravo, B. (1982). Bello y la judicatura: La reforma judicial. Ahora en Bravo, B. (2006). El juez entre el derecho y la ley. Santiago: LexisNexis.

Bravo, B. (1983). Los comienzos de la codificación en Chile: La codificación procesal. Ahora en BRAVO, B. (2006). El juez entre el derecho y la ley en el mundo hispánico. Santiago: LexisNexis.

Bravo, B. (1985). Vigencia de las Partidas en Chile. REHJ, 10.

Bravo, B. (1990). Odia restring: Forma y destino de una regla de derecho en Europa e Iberoamérica, durante la Edad Moderna. Ahora en Bravo, B. (2006). El juez entre el derecho y la ley. Santiago: LexisNexis.

Bravo, B. (1991) Arbitrio judicial y legalismo: El juez frente al derecho antes y después de la codificación en Europa e lberoamérica. Ahora en Bravo, B. (2006). El juez entre el derecho y la ley. Santiago: LexisNexis.

Bravo, B. (1991). ludex, minister aequitatis. Ahora en Bravo, B. (2006). El juez entre el derecho y la ley en el mundo 
hispánico. Santiago: LexisNexis.

Bravo, B. (1998). Estudios de derecho y cultura de abogados en Chile: 1758-1998. Ahora en Bravo, B. (2006). El juez entre el derecho y la ley en el mundo hispánico. Santiago: LexisNexis.

Bravo-Hurtado, P. (2013). Hacia los precedentes en Chile: Reforma procesal Civil y fuentes del derecho. RCHD, 40 (2).

Campillo, C. (1863). Algunas lijereras indicaciones sobre el uso que corresponde en los fundamentos de los fallos judiciales al artículo 1545 del Código Civil. AUCh., 23.

Carvajal, P-I. (2012). Discurso académico de lanzamiento de la Revista Chilena de Derecho y Ciencia Política. RCHDCP, 3 (1).

Claro L. (1898-1944). Explicaciones de derecho civil chileno y comparado. Santiago: Imp. El ImparcialEstablecimiento Poligráfico Roma-Imprenta Cervantes, I.

Coo, A. (1896). Concordancias de la Lei de Organización i Atribuciones de los Tribunales con la lejislación chilena. Santiago: Imprenta i encuadernación Roma.

Cood, E. y Fabres, J. C. (1882). Explicaciones de Código Civil destinadas a los estudiantes del ramo en la Universidad de Chile. Santiago: Imprenta Cervantes.

De Armas, J. A. (1886). Comentario de siete títulos del Código Civil. Santiago: Imprenta de la Unión.

Chacón, J. (1868-1882). Esposición razonada y estudio comparativo del código civil chileno. Valparaíso: Imprenta del Mercurio, de Recaredo S., I.

Domínguez, R. (2005). La influencia de la doctrina francesa en el derecho chileno. CAJ, 2.

Donoso, J. (1857). Diccionario teolójico, canónico, jurídico, litúrjico, bíblico, etc. Valparaíso: Imprenta i librería del Mercurio, III.

Dougnac, A. (1994). Manual de Historia del Derecho Indiano. Ciudad de México: Universidad Nacional Autónoma de México.

Ducci C. (1995). Derecho civil. Parte general (4a. ed.). Santiago: Editorial Jurídica de Chile.

Fabres, J. C. (1863). Instituciones de derecho civil chileno. Valparaíso: Imp. del Universo de G. Helfmann.

Fabres, J. C. (1893-1902). Instituciones de derecho civil chileno (2da. Ed.). Santiago: Imp. y Librería Ercilla.

Fernández, J. M. (1864). Exposición del art. 1554 del Código civil, sobre la obligación que nace de la simple promesa de celebrar un contrato, i de una sentencia en que se relaciona con él. AUCh, 25.

Figueroa, M. A. (1982). La codificación civil chilena y la estructuración de un sistema jurídico legalista En Bello y el derech., Santiago: Editorial Jurídica de Chile.

Guzmán, A. (1980). Algunas actas de sesiones de la comisión revisora del proyecto de Código civil de 1853. REHJ, 5.

Guzmán, A. (1982). Andrés Bello codificador. Santiago: Ediciones de la Universidad de Chile, I.

Guzmán, A. (1982). Historia del "referimiento al legislador", II: el derecho nacional chileno. REHJ, 7.

Guzmán, A. (1992). El Código Civil de Chile y sus primeros intérpretes. RCHD, 19 (1).

Guzmán, A. (2005). La influencia del Código Civil francés en las codificaciones americanas. CAJ, 2.

Guzmán, A. (2011). Las reglas del Código Civil de Chile sobre interpretación de las leyes. Santiago: LexisNexis.

Guzmán, R. (1983). Índice de la revista "Gaceta de los Tribunales" 1841-1860. REHJ, 8.

Hanisch, H. (1982). Contribución al estudio del principio y práctica de la fundamentación de las sentencias en Chile durante el siglo XIX. REHJ, 7.

Lastarria, J. V. (1865). Elementos de derecho público, constitucional, teórico, positivo y político. Gante: Imprenta de Eug. Vanderhaeghen.

Levaggi, A. (1978). La fundamentación de las sentencias en el derecho indiano. RHD, 6.

Lira, J. B. (1880-1881) Prontuario de los juicios (3a. ed.). Santiago: Imprenta del Correo de Ramón Varela, I.

Lira, P. (1956). El Código Civil chileno y su época. Santiago: Editorial Jurídica de Chile.

Martínez, S. (2008). El derecho castellano-indiano en el Código Civil de Bello. RCHHD, 20. 


\section{Claudio Barahona Gallardo}

Merello, I. (1983). La ley mariana de fundamentación de sentencias frente a la clemencia judicial en materia penal. REHJ, 8.

Novísima Recopilación de las leyes de España. Madrid: Imprenta de la Publicidad, IX.

Pacheco, M. (1990). Teoría del derecho (4a. ed.). Santiago: Editorial Jurídica de Chile.

Pescio, V. (1948). Manual de Derecho Civil. Santiago: Nascimento, I.

Ramírez, T. (1907). Explicaciones de derecho civil. Santiago: Imprenta Universitaria.

Risopatrón, C. (1900). Comentario a la Ley de Organización y Atribuciones de los Tribunales de Chile. Santiago: Imprenta, encuadernación i litografía Barcelona.

Robles, L. (1864). Concordancia de la teología moral con el Código Civil chileno, en los tratados de derecho, justicia i contratos. Santiago: Imprenta Nacional.

Roldán, A. (1913). Elementos de derecho constitucional de Chile. Santiago: Imprenta Barcelona.

Squella, A. (2000). Introducción al derecho. Santiago: Editorial Jurídica de Chile.

Siete Partidas (1848). Madrid: Imprenta de la Publicidad, II.

TAU, V. (1992). Casuismo y sistema: Indagación histórica sobre el espíritu del Derecho Indiano. Buenos Aires: Instituto de Investigaciones de Historia del Derecho.

Ugarte, F. (1869). De los actos de comercio en su relación con la competencia de jurisdicción. Santiago: Imprenta de El Independiente.

Vargas, F. (1864). Proyecto de Lei de Organización i Atribuciones de los Tribunales. Santiago: Imprenta Nacional.

Vera, R. (1892-1897). Código civil de la república de Chile, comentado i esplicado. Santiago: Impr. Gutenberg, 1892-1897, I.

Vera, R. (1894). Ley de Organización y Atribuciones de los Tribunales arreglada y anotada (2a. ed.). Santiago: Imprenta Benjamín Vicuña Mackenna.

Vodanovic, A. (2001). Manual de derecho civil. Partes preliminar y general (2a. ed.). Santiago: Editorial Jurídica ConoSur Ltda.

\section{Abreviaturas}

AFJS: $\quad$ Anuario de Filosofía Jurídica y Social

AJ: $\quad$ Actualidad Jurídica

CAJ: $\quad$ Cuadernos de Análisis Jurídico

RCHD: $\quad$ Revista Chilena de Derecho

RCHDCP: $\quad$ Revista Chilena de Derecho y Ciencia Política

RCHHD: Revista Chilena de Historia del Derecho

RCsSVa.: Revista de Ciencias Sociales de la Universidad de Valparaíso

RDPUCV: Revista de Derecho de la Pontificia Universidad Católica de Valparaíso

RDUCN: Revista de Derecho de la Universidad Católica del Norte

RDUCT: $\quad$ Revista de Derecho de la Universidad Católica de Temuco

REDJD: $\quad$ Revista Estudios Jurídicos Democracia y Justicia (Universidad de Talca)

REHJ: $\quad$ Revista de Estudios Histórico-Jurídicos

REJ: $\quad$ Revista de Estudios de la Justicia

REJud.: $\quad$ Revista de Estudios Judiciales (Instituto de Estudios Judiciales Hernán Correa de la Cerda)

RHD: $\quad$ Revista de Historia del Derecho (Instituto de Investigaciones de Historia del Derecho)

RIPr: $\quad$ Revista lus et Praxis 